\title{
The Effect of Home Computer Use on Children's Cognitive and Non-Cognitive Skills
}

\author{
M. Fiorini ${ }^{1}$ \\ School of Finance and Economics, University of Technology Sydney, Broadway NSW 2007, \\ Australia
}

\begin{abstract}
In this paper we investigate the effect of using a home computer on children's development. In most OECD countries $70 \%$ or more of the households have a computer at home and children use computers quite extensively, even at very young ages. We use data from the Longitudinal Study of Australian Children (LSAC), which follows an Australian cohort born in 1999/2000. Skills and computer usage information is collected when children are approximately 5 and 7 years old. For cognitive skills, our results indicate that computer time has a positive effect. For non-cognitive skills the evidence is mixed, the effect depending on the score and the age of the children. We test the robustness of our results by comparing OLS, IV and Value Added estimators. Generally, the IV estimates are larger and the Value Added estimates lower than the OLS ones. However the pattern of the results is quite consistent. (I2,J13,J24)
\end{abstract}

Key words: human capital, productivity

\section{Introduction}

In the last decade a number of papers have stressed that educational and labor market outcomes are largely pre-determined by the cognitive and noncognitive skills accumulated during early childhood. Keane and Wolpin (1997, 2001), Cameron and Heckman $(1998,2001)$ have found that in the US individual educational decisions are mainly driven by cognitive skills such as maths and verbal skills. Heckman, Stixrud, and Urzua (2006) find that a low-dimensional model of cognitive and non-cognitive abilities explains a diverse array of outcomes such as schooling choices, wages, employment, work experience, choice of occupation but also a variety of adolescent risky behaviors such as criminality, cigarette smoking and alcohol use. Cunha, Heckman, and Lochner (2006) conclude that ability gaps in both cognitive and non-cognitive skills across indi-

\footnotetext{
Email address: mario.fiorini@uts.edu.au (M. Fiorini )

${ }^{1}$ Tel: +61 295143339
} 
viduals and across socioeconomic groups open up early in the life cycle and IQ deficits need to be addressed at very early ages for interventions to be effective.

Given this evidence, there is a growing interest in estimating the skills production function. Researchers are trying to uncover the main inputs and their time varying effect (see Todd and Wolpin (2003, 2007) and Cunha and Heckman (2007) for a discussion). However, estimating the causal effect of these inputs is difficult because all sorts of endogeneity problems might lead to inconsistent estimates and economists have mainly focused on a few inputs that are either very important or for which experimental designs are available. To mention only a few recent studies that have looked at the determinants of math and reading achievements: Dahl and Lochner (2005) estimate the effect of parental income, Bernal and Keane (2009) and Baker and Milligan (2008) look at the effect of child care, Berlinski, Galiani, and Manacorda (2008) evaluate the effect of pre-school while Gentzkow and Shapiro (2008) identify the effect of pre-school television exposure.

The objective of this paper is to investigate the effect of using a computer at home. Computers are a relatively new input in the production function. Figure 1 shows OECD data on home computer access in a few selected countries. ${ }^{2}$ There is a clear upward trend. Since 2005, in all the countries $70 \%$ or more of the households had a computer at home and this proportion is likely to rise further. As we show below, children use home computers quite extensively. Yet, little is known about the effect of computer usage on children's cognitive and non-cognitive skills.

Psychologists have long investigated the effect of time spent in front of the television on children's development, see Schmidt and Anderson (2007) for a review, and are now shifting their attention to computers, see Subrahmanyam, Greenfield, Kraut, and Gross (2001). Even though computers and TV are different media devices, understanding why TV time can have an effect on children's skills is a useful starting point to analyze the effect of computer time. There are three main theories in psychology. The first theory emphasizes the effect of TV content, that is what matters is what children watch and not TV time per se. On the one hand, this theory states that educational programs can have a positive effect on skills. On the other hand, if children watch mostly cartoons or general entertainment programs, TV would have no impact. The second theory points at the time allocation problem. Children, like adults, have a limited time endowment. The more time is spent watching TV, the less time is available for other activities. If TV time displaces other educational or social activities then it might have an effect even irrespectively of what children watch. The third theory points at the passive nature of television. Viewing requires little overt behavior, programs are visually explicit and require little visual imagination, and the medium is not interactive. As a result children might become intellec-

\footnotetext{
${ }^{2}$ Data for the USA is available for only a few years. OECD Key ICT indicators available at http://www.oecd.org/document/23/0,3343, en_2649_34449_33987543_1_1_1_37441, 00.html
} 


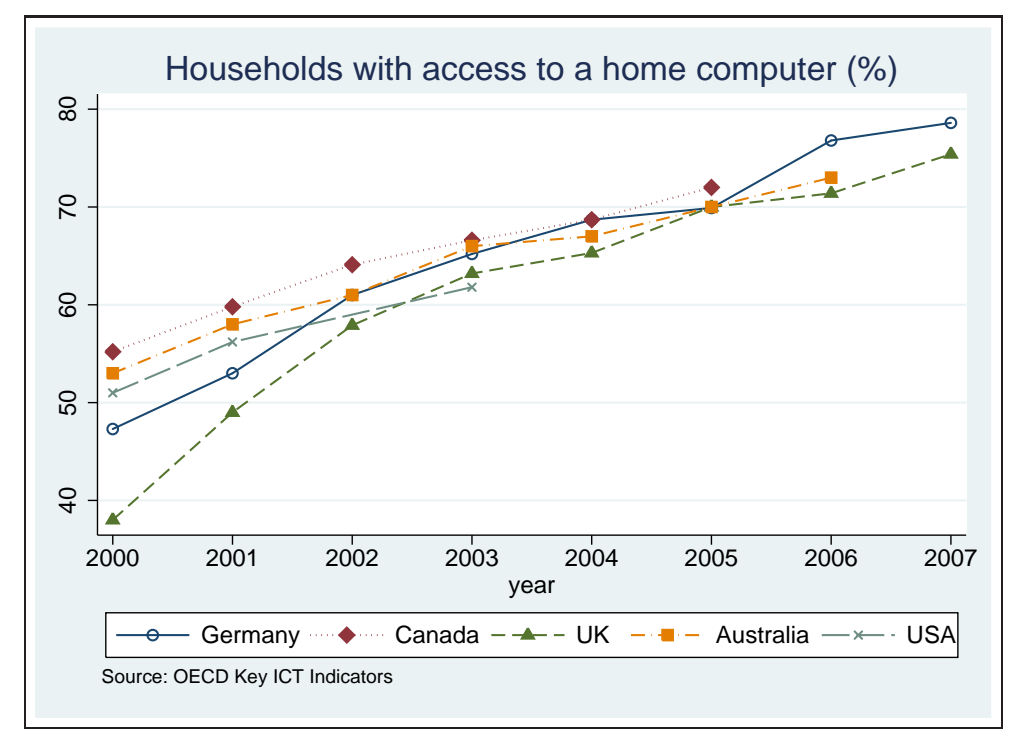

Figure 1: Household Home Computer Access

tually passive. While we refer the reader to section 2 for a more complete review of the literature, we anticipate that psychology studies conclude that the effect of watching TV strongly depends on the content of the programs watched (educational programs having a positive effect) and on the socio-economic status of the parents (children with low status parents benefiting more from TV), the latter reflecting the quality of those activities displaced by TV time. Computers and TV share some similarities but there are also major differences. Computers imply more freedom with respect to content, since there is a very large variety of software or internet content to choose from. Computers are also more interactive than $\mathrm{TV}$, with most software requiring continuous inputs from the users. Still, most of the above discussion can be extended to computer time. Content can matter, other activities will be displaced by computer time, and computer use can be intellectually challenging (rather than intellectually passive).

In this paper we use the Longitudinal Study of Australian Children (LSAC) data, which follows an Australian cohort born in 1999/2000. Data for this cohort were collected in two surveys (2004 and 2006) when children were aged 4/5 and $6 / 7$ years old. The advantage of this data lies in its longitudinal nature, coupled with information about cognitive and non-cognitive test scores and information on computer access. In particular information was collected not only on whether the child had access to a computer at home, but also on the number of hours he/she would use the computer on a typical weekday and weekend. The LSAC data shows that by the age of 7 around $88 \%$ of the children had access to a computer at home. This is an even larger fraction than the $70 \%$ reported in figure 1, probably due to the fact that these children had young parents who 
are more likely to use modern technologies. From these data it also emerges that the average child with access to a computer spends almost 3 hours in front of a computer every week. Children also make extensive use of other devices spending 13 hours watching TV/DVD's and 3 and almost two hours playing with video game consoles such as PlayStation, XBox and Nintendo every week. If we are interested in the skill production function we can not neglect the importance of these inputs given that they absorb a considerable amount of time. Here we mainly focus on computer use though we also try to shed some light on the effect of TV/DVD's and video game use. We look at both cognitive and non-cognitive skills. Both types of skills might be affected by the content (educational software, games, emailing or messaging, other internet use) but also by the displaced activities. If, for instance, computer time displaces reading books or other educational activities, cognitive skills might be affected. Similarly, if computer time displaces social activities, with parents or other children, non-cognitive skills could be influenced.

Previous research has focused on the effect of TV on skills, of computers in schools or on the effect of a home computer on high school completion. Our paper contributes to the existing human capital literature by focusing on the effect of home computer use on early childhood cognitive and non-cognitive skill development. To our knowledge no other economic study has tried to address this question so far.

In the remainder of the paper we first discuss the skills production function and the assumptions needed to identify the causal effect of computer use on cognitive and non-cognitive skills. We rely on a rich set of controls available in the LSAC, and assess the robustness of our results by comparing alternative estimators. We follow Todd and Wolpin (2003, 2007) and compare OLS, IV and Value Added estimators. Our results indicate that children using computers are more likely to score better in cognitive skill tests. Computer use matters mainly during the weekend, and the effects are larger for girls and for children with low educated parents. The evidence for non-cognitive skills is mixed.

The paper unfolds as follows: In section 2 we review the main findings of the computer literature. Section 3 introduces the skill production function and then discusses the identification of the parameters of interest. Section 4 presents the cohort data used in the analysis. Section 5 presents our findings. Section 6 concludes.

\section{Literature}

The literature evaluating the impact of computer access and use on children's outcomes is still rather limited. This is probably due to the fact that computers entered schools and houses on a large scale only in the last 10 to 15 years. In this section we give a short summary of those studies evaluating the effect of computer and TV use on educational attainment and cognitive skills. 


\subsection{Effect of Home Computer use}

Schmitt and Wadsworth (2006) explore the link between ownership of a home computer at ages 15 and 17 and subsequent achievements in the principal British school examinations taken at ages 16 (GCSEs) and 18 (A-levels). Using the British Household Panel Survey (BHPS), they estimate the causal effect using a probit model where identification relies on a rich set of controls such as household income, mother and father's education, mother and father's age and number of dependent children living in the household. The data show a significant positive association between $\mathrm{PC}$ ownership and the qualifications obtained. The frequency of PC use also appears to be weakly correlated with positive educational outcomes at age 16 .

Beltran, Das, and Fairlie (2008) look into the relationship between computer ownership and high school graduation in the US, using recent panel data from matched CPS files and the NLSY97. Using a probit model with a rich set of controls, they find that home computers are associated with a 6-8 percentage point higher probability of graduating from high school. They also estimate a bivariate probit model for the joint probability of computer ownership and high school graduation using parental use of the Internet at work and the presence of another teenager in the household as instruments. The bivariate probit leads to coefficient estimates that are similar to the original probit estimates, although statistically insignificant.

Subrahmanyam, Greenfield, Kraut, and Gross (2001) survey the psychology literature. Several studies provide preliminary evidence that computer use is positively correlated with academic achievement. Few studies have examined the effect of children's time on computers on their social skills and friendships. The existing research suggests that frequent game players actually meet friends outside school more often than less frequent players and no differences have been found in the social interactions of computer game players vs. non-players. However most of these results apply to teenagers.

\subsection{Effect of School Computer use}

Angrist and Lavy (2002) assess the short-run consequences of increased computer-aided instruction (CAI) technology in Israeli schools. They find a consistently negative and marginally significant relationship between the programme induced use of computers and 4th grade Maths scores. For other grades and subjects the estimates are not significant, though also mostly negative.

Rouse and Krueger (2004) present results from a randomized study of a welldefined program of computer use in US schools (grade 3 to 6): an instructional computer program, known as Fast ForWord, which is designed to improve language and reading skills. Their estimates suggest that while use of the computer program may improve some aspects of pupils' language skills, it does not appear that these gains translate into a broader measure of language acquisition or into actual reading skills.

Barrow, Markham, and Rouse (2009) similarly use another randomized study to analyze the effect of an instructional computer program which is designed to 
teach pre-algebra and algebra. They find that, in 3 US mid and high school districts, students randomly assigned to computer-aided instruction score at least 0.17 of a standard deviation higher on a pre- algebra/algebra test than students randomly assigned to traditional instruction.

Banerjee, Cole, Duflo, and Linden (2007) look at the results of a randomized experiment conducted in schools in urban India (grade 3 and 4). A computerassisted learning program was randomly assigned to some schools for up to two years. The program was found to be very effective, increasing math scores by 0.36 standard deviations the first year, and by 0.54 standard deviation the second year.

\subsection{Effect of $T V$ use}

To conclude our literature review we summarize the main findings on the effect of TV time on children's skills. Gentzkow and Shapiro (2008) look the effect of preschool television exposure in the 1950's on standardized test scores later in life. Using heterogeneity in the timing of television's introduction as a source of identification, they find that an additional year of preschool television exposure raises average test scores by about .02 standard deviations. These effects are largest for children from households where English is not the primary language, for children whose mothers have less than a high school education, and for non-white children.

Schmidt and Anderson (2007) provide an overview of the findings in the psychology literature. Exposure to educational programs, such as Sesame Street, has a positive effect on children's vocabulary learning and this effect is long lasting. They do not find evidence that TV displaces intellectually valuable activities. In fact $\mathrm{TV}$ replaces activities similar to $\mathrm{TV}$ viewing such as radio listening, comic book reading and moviegoing.

\section{The Production Function}

In our data we observe the children at two points in time, when they are aged $4 / 5$ (2004) and 6/7 (2006). Since it is unlikely that they made extensive use of a computer before age 4 , let us start with a simple two period model $t=1,2$. Denote by $C_{t}$ computer time at time $t$, by $F I_{t}$ a vector of family inputs, by $S I_{t}$ a vector of school inputs and by $O M_{t}$ time spent using other media devices such as TV and video games. Let $\mu$ denote children's unobserved time constant endowments (like innate abilities). Here $\mu$ is not 1 -dimensional but rather a vector including a range of cognitive and non-cognitive innate abilities. Finally, denote by $T_{j t}$ the $j^{t h}$ test score measured at time $t$ and by $\epsilon_{t}$ the measurement error in $T_{j t}$. The main cognitive and non-cognitive skills are summarized in a vector of test scores $T$.

\subsection{Period 1}

The production function of each test score in period 1 can be written as: 


$$
T_{j 1}=g_{j}\left(C_{1}, F I_{1}, S I_{1}, O M_{1}, \mu, \epsilon_{1}\right)
$$

where we are assuming that any non-media input enters either $F I_{1}$ or $S I_{1}$. In this paper our parameter of interest is the effect of $C_{1}$ on $T_{j 1}$, holding all other inputs constant. It is easy to see why the identification of this parameter is complicated by endogeneity problems. $C_{1}$ depends on the parental decision to own and make available a computer but also on the child decision to spend some time using it. Unobserved family, school and media inputs together with the child's innate abilities might be correlated with $C_{1}$ but also $T_{j 1}$. Measurement error in $C_{1}$ can instead cause attenuation bias. In the data the parents were asked to report the time their children spent using the computer. It is possible that some parents could only provide a rough guess. Therefore $\epsilon_{1}$ can include measurement error in $C_{1}{ }^{3}$

Todd and Wolpin $(2003,2007)$ discuss alternative estimation strategies under the assumption that the $g$ function is linear, an assumption that we also make. Let $X_{1}$ denote observed family, school and other media inputs and let $U_{1}$ denote the unobserved ones.

$$
T_{j 1}=\alpha_{j 1}+\beta_{j 1} C_{1}+X_{1} \gamma_{j 1}+v_{j 1}
$$

where $v_{j 1}=U_{1} \delta_{j 1}+\mu \rho_{j 1}+\epsilon_{1}\left(\gamma_{j 1}, \delta_{j 1}, \rho_{j 1}\right.$ are vectors $)$. The simplest way to estimate equation (2) is to use the OLS estimator and assume that we can control for the most important inputs influencing both $C_{1}$ and $T_{j 1}$ such that $E\left(v_{j 1}^{\prime} C_{1}\right)=0$. The LSAC survey designers put a lot of care in collecting very detailed information regarding parental background, home and school care. In the results section we discuss what variables we can use to account for the family, school and other media inputs and to proxy for innate abilities of the child $\mu$. Yet even rich data can rarely allow to perfectly control for these innate abilities. One possibility is to assume that the parental decision to own a computer is not a function of $\mu$. That is parents own a computer mainly for their work, internet browsing or other personal uses so that the ownership decision does not depend on the children's characteristics. ${ }^{4}$ If this is the case, and there are no other unobservable entering both the parental decision and the production function, than computer ownership $H C_{1}$ can serve as an instrument for $C_{1}$ since $E\left(v_{j 1}^{\prime} H C_{1}\right)=0$ but $E\left(H C_{1}^{\prime} C_{1}\right) \neq 0 .{ }^{5}$ Using an IV is also the only way to solve

\footnotetext{
${ }^{3}$ Test scores are the best available proxy of true skills, but they are still likely to measure these skills with errors. Thus skills's measurement error might also enter $\epsilon_{1}$.

${ }^{4}$ In the data, parents were not asked whether they had a home computer but rather whether the child had access to one. Therefore parents had to take two decisions: whether to own a home computer and whether to make it available to the child. The latter could be correlated with $\mu$. From the data, we only know whether the child had access to a computer at home. However, since in wave 1 (wave 2) $77 \%$ (88\%) of the children had access to one, it is unlikely that many parents had a computer but did not make it available. That reduces the choice space to a simple ownership decision.

${ }^{5}$ One argument against $H C_{1}$ satisfying the exclusion restriction is time displacement. Since the parents own a computer, presumably they spend some time using it. If parental computer
} 
the measurement error problem. Nevertheless, under heterogenous treatment effects the IV estimator will identify the Average Treatment on the Treated (ATT) and not the ATE. ${ }^{6}$

In period 1 it is also possible to test the robustness of OLS estimates by including a future measure of computer use $C_{2}$ in equation (2). Conditional on $C_{1}$, future computer use should not be correlated with $T_{j 1}$ unless $\mu$ or $U_{1}$ are correlated with $C_{2} \cdot{ }^{7}$

\subsection{Period 2}

The production function in period 2 is:

$$
T_{j 2}=g_{j}\left(C_{2: 1}, F I_{2: 1}, S I_{2: 1}, O M_{2: 1}, \mu, \epsilon_{2}\right)
$$

where the subscript 2:1 indicates that we include both period 2 and 1 inputs. Every input of the production function at time 2 can have an effect on $T_{j 2}$ through its contemporaneous or lagged level. This is true also for computers where use in period 1 (age $4 / 5$ in our data) might have permanent effects on the test scores besides the effect on $C_{2}$. If we only include $C_{2}$ its coefficient would pick up the effect of the whole computer history but we would not know when this input is most effective. According to Cunha, Heckman, and Lochner (2006) the timing of inputs matters because some skills can be shaped only when children are very young. Once again we assume that the production function is linear in its inputs:

$$
T_{j 2}=\alpha_{2}+C_{2: 1} \beta_{j 2}+X_{2: 1} \gamma_{j 2}+v_{j 2}
$$

where $v_{j 2}=U_{2: 1} \delta_{j 2}+\mu \rho_{j 2}+\epsilon_{2}$. Therefore in equation (4) we are interested in estimating $\beta_{2}$ which is a $2 \times 1$ vector. The estimation of this equation is once again plagued by endogeneity problems potentially even more severe since now we are interested in the causal effect of the two endogenous variables $C_{1}$ and $C_{2}$. Besides OLS, Instrumental Variable estimation is still possible using $H C_{1}$ and $H_{2}$ as instruments provided they are not multicollinear. However, consistency of the IV estimator now requires very strong restrictions on the time 2 parental decision. For $E\left(v_{j 2}^{\prime} H C_{2}\right)=0$ to hold, the parental decision to own a computer at $t=2$ must be uncorrelated with $C_{1}$ and $T_{1}$, since these are a function of $\mu$, and $T_{1}$ is also a function of $U_{1}$. Todd and Wolpin $(2003,2007)$ discuss the estimation of the production function (4) using the Value Added model. The idea is to include a lagged test score $T_{j 1}$ on the right hand side. Intuitively, since

time displaces time with the child, or time otherwise invested in producing $T_{j 1}$ inputs that we do not control for, then $E\left(v_{j 1}^{\prime} H C_{1}\right) \neq 0$. However, if parental computer time displaces "unproductive" time, for instance parental TV time, then the exclusion restriction holds.

${ }^{6}$ To see this note that under heterogenous treatment effects $\beta_{j 1, i}$ the IV estimator would recover the $\mathrm{LATE}=E\left[\beta_{j 1, i} \mid C_{1}\left(H C_{1}=1\right)-C_{1}\left(H C_{1}=0\right)>0\right]$ but since $C_{1}\left(H C_{1}=0\right)=0$ by definition, the LATE $=\mathrm{ATT}=E\left(\beta_{j 1, i} \mid C_{1}>0\right)$.

${ }^{7}$ However, even if $E\left(C_{2}^{\prime} \mu\right)=E\left(C_{2}^{\prime} U_{1}\right)=0, C_{2}$ might be correlated with $\epsilon_{1}$. This would happen if $C_{2}$ is a function of previous period test scores $T_{1}$. 
the lagged test score is a function of $\mu$, including it among the control variables might reduce the omitted variable bias. However Todd and Wolpin (2003, 2007) also show that the Value Added model solves the endogeneity problem only if the impact of the ability endowment $\mu$ declines over time at a rate equal to the first order correlation across test scores. ${ }^{8}$ Finally it is also possible to estimate the production function through the First Difference (or Fixed Effect) estimator. This estimator relies on other strong assumptions. The first two terms of $v$ must be time constant, that is $\left(U_{2: 1} \delta_{j 2}+\mu \rho_{j 2}\right)-\left(U_{1} \delta_{j 1}+\mu \rho_{j 1}\right)=0$. Even if $C_{2: 1}$ was orthogonal to $U_{2: 1}$, the ability endowment must have a constant effect over time, $\rho_{j 2}=\rho_{j 1}$. In principle there is no reason why this should be the case and this equality holds for all the cognitive and non-cognitive abilities in the $\mu$ vector. Also, First Difference requires strict exogeneity. However this would be violated whenever $C_{2}$ is a function of $T_{1}$ either through the parental or children choice functions, since in that case $E\left(C_{2}^{\prime} \epsilon_{1}\right) \neq 0$.

Later in the paper we provide estimates of the linear production functions in period 1 and 2 . There are two main reasons why we estimate both functions rather than just the one in period 2. First, if some learning processes exists, investments or choices are made at very young ages, $T_{1}$ might have a role even conditional on $T_{2}$. Second, in the data the vector of cognitive skill scores between period 1 and 2 is not the same, since some tests are age specific. Therefore the outputs of the production functions are not identical in the two periods. We refer to the data section for a more complete explanation of the cognitive skills measures.

\section{Data}

The data come from the Longitudinal Study of Australian Children (LSAC). During 2004, the study recruited a sample of 5,107 infants (children born March 2003-February 2004) and 4,983 children aged 4-5 years (children born March 1999-February 2000) in a dual cohort cross-sequential design. It is intended that these children and their families will be interviewed biannually until 2010, and possibly beyond. Data for the first two waves of each cohort are now available. In what follows we focus on the older cohort, aged on average 4 years and 9 months at the time of the first survey and 6 years and 10 months at the time of the second one. We then create our sample by selecting those children for

\footnotetext{
${ }^{8}$ This can be easily seen under linearity. Using equations (2) and (4), and letting ' and " indicate the first and second element of the vectors $\beta, \gamma, \delta$ :

$$
\begin{aligned}
T_{j 2}-\phi T_{j 1}= & \left(\alpha_{2}-\phi \alpha_{1}\right)+\beta_{2}^{\prime \prime} C_{2}+\left(\beta_{2}^{\prime}-\phi \beta_{1}\right) C_{1}+X_{2} \gamma_{2}^{\prime \prime}+X_{1}\left(\gamma_{2}^{\prime}-\phi \gamma_{1}\right) \\
& +U_{2} \delta_{2}^{\prime \prime}+U_{1}\left(\delta_{2}^{\prime}-\phi \delta_{1}\right)+\left(\rho_{2}-\phi \rho_{1}\right) \mu+\epsilon_{2}-\phi \epsilon_{1}
\end{aligned}
$$

This also shows that $U_{2}$ and $U_{1}$ still enter the error term unless $\delta_{2}^{\prime \prime}=\left(\delta_{2}^{\prime}-\phi \delta_{1}\right)=0$. Moreover, $C_{2}$ will be correlated with $\epsilon_{1}$ if previous test scores enter the parental or children choice functions.
} 
whom data were collected at both waves, corresponding to $90 \%$ of the original sample.

\subsection{Computer Access and Use}

In Wave 1 parents were asked whether the study child had access to a computer at home and if so, how many hours the child used the computer on a typical weekday and on a typical weekend day. Unfortunately in Wave 1 the number of hours were recorded in bands and not in continuous form. ${ }^{9}$ Parents were also asked about the number of televisions at home and how many hours the child spent watching TV (still distinguishing between a weekday and weekend, and with hours coded in bands).

In Wave 2 parents were asked the same questions though this time computer and TV use were recorded as continuous variables. Moreover, in this second wave parents were also asked whether the children had access to a video game console such as Xbox, Playstation or Nintendo and if so, how many hours (weekday/weekend) they spent using it. Finally, the question on the total number of TV's in the house was replaced by a question asking whether the child had one in his/her own bedroom.

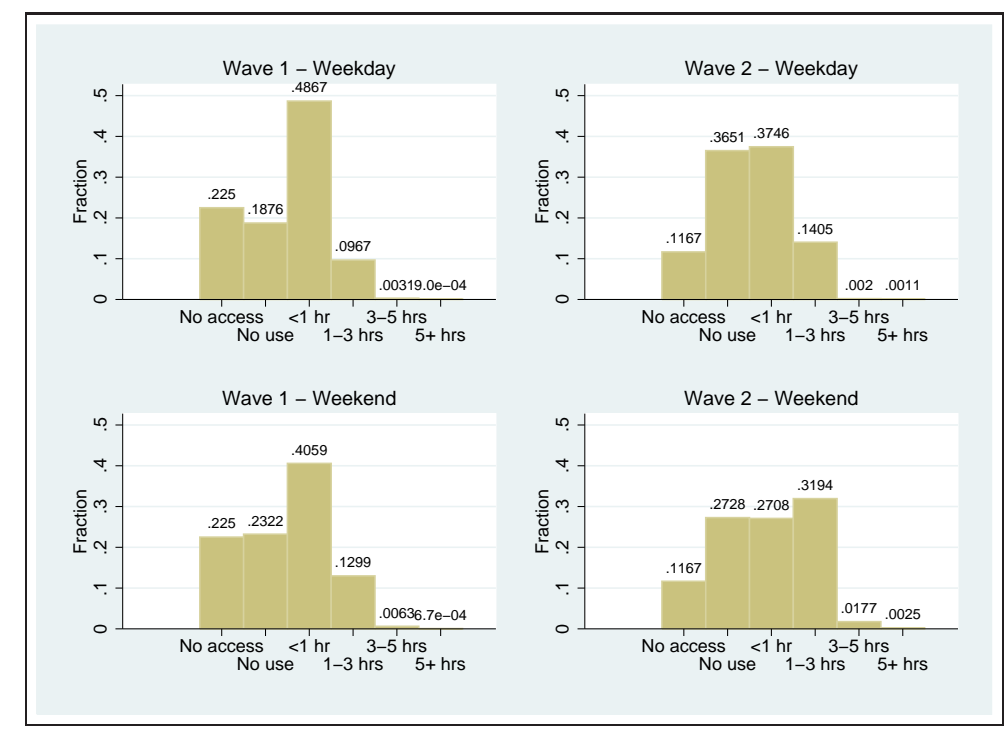

Figure 2: Home Computer Access and Use

Figure 2 shows computer access and use in waves 1 and 2. We distinguish between children who had no access to a computer (No access), those who had

\footnotetext{
${ }^{9}$ The 5 bands were coded as follow: 1 . Five or more hours; 2 . From three to five hours; 3. From one to three hours; 4 . Less than one hour; 5 . No use.
} 
access but did not use it (No use) and those who had access and spent some time using it, where computer time is coded in 4 discrete hour bands $(<1 \mathrm{hr}$, 1-3hrs, 3-5hrs, 5+hrs).

Children were more likely to have access to a computer in wave 2. By then only $11.67 \%$ of children could not access one. Perhaps parents decided to let the children use the computer as the children became older and started school or it could be simply the result of the upward trend in computer ownership that we have seen in figure 1.

\begin{tabular}{l|cc|cc}
\multicolumn{3}{c}{ Table 1: Media Access and Use } \\
\hline \hline & \multicolumn{3}{|c}{ Wave 1 } & \multicolumn{2}{c}{ Wave 2 } \\
\hline & Mean & SD & Mean & SD \\
PC Access & 0.78 & 0.42 & 0.88 & 0.32 \\
PC hrs weekdays & 1.79 & 2.28 & 1.68 & 2.68 \\
PC hrs weekends & 0.71 & 0.85 & 1.21 & 1.51 \\
Number of TV's & 1.80 & 0.85 & - & - \\
TV in bedroom & - & - & 0.17 & 0.37 \\
TV/DVD hrs weekdays & 8.30 & 4.73 & 8.08 & 5.42 \\
TV/DVD hrs weekends & 3.90 & 2.06 & 4.82 & 2.89 \\
Video Game console & - & - & 0.54 & 0.50 \\
VG hrs weekdays & - & - & 0.85 & 2.20 \\
VG hrs weekends & - & - & 0.98 & 1.71 \\
\hline Observations & \multicolumn{4}{|c}{4464} \\
\hline \hline
\end{tabular}

Table 1 presents basic statistics on the use of computers, TV and video games. In order to construct the figures in table 1 (Wave 1) we recoded number of hours in continuous form. For both computer and TV hours, we used the median number of hours within each band from wave 2 and imputed that figure for wave 1 observations. ${ }^{10}$ The average child was using the computer for a total of 1.79 hours during the week, and a total of 0.71 hours during the weekend. Importantly, there is evidence of variation over time. Not reported, the correlation between $C_{1}$ and $C_{2}$ is equal to 0.25 . If $C_{1}$ and $C_{2}$ were to be multicollinear, estimation of equation (4) would be problematic resulting in large standard errors. Children also spent 8 hours watching TV during the weekdays and almost 4 hours during the weekend. In wave 2, when children were aged between 6 and 7 years old, almost everyone had access to a computer at home. Compared to wave 1 , children used it less during the weekdays but more during the weekend, and a similar pattern exists also for TV use. Since in wave 2 children were aged 6 to 7 years old, and therefore all enrolled in school, it is possible that they had less home time during the week. Parents were also asked whether the child had his/her own TV in the bedroom. Almost one in five children had one. However no information was collected about the number of televisions at home. Finally in wave 2 more than half of the children had a video game console. There are

\footnotetext{
${ }^{10}$ Say that in wave 2 the median number of minutes for those children in the ' 1 to 3 hours' was 150 , then we would impute 150 minutes also for those children that in wave 1 fall within this ' 1 to 3 hours' band.
} 
some differences across gender: overall, at wave 2 an average (median) boy spent around 19 (17) hours using a combination of computer, TV and video games, while an average (median) girl spent 16 (14) hours.

None of the first two LSAC waves contain information on what the children used the computer for. However, in August 2007 a short questionnaire (Wave 2.5) was sent to the study families, which contain age appropriate questions on childrens engagement with media and technology. Unfortunately these data have some limitations. First, only $65 \%$ of the original sample mailed back the questionnaire and even then there are many cases with missing values. Second, information about the child's age at the time the questionnaire was completed or the date of interview are not provided. Third, no cognitive skill test was administered, and only a restricted subset of the Wave 1 and 2 non-cognitive variables is provided. Finally, we could still think of computer activities at Wave 2.5 as being a proxy for activities at earlier waves, but this might be a too strong assumption, particularly for Wave 1. With this in mind, table 2 shows computer use by activity at Wave 2.5. The most common use of computers was gaming, followed by school work and DVDs/CDs playing. ${ }^{11}$

Table 2: Wave 2.5 Computer Activities

\begin{tabular}{l|ccc}
\hline \hline & Play DVDs/CDs & Do School Work & Play Games \\
\hline No Home PC & 5.39 & 5.39 & 5.39 \\
never & 41.53 & 24.22 & 6.76 \\
less than once a week & 25.70 & 41.39 & 33.16 \\
1-2 times a week & 16.37 & 16.58 & 30.02 \\
3-4 times a week & 7.85 & 7.00 & 17.35 \\
daily & 3.17 & 5.42 & 7.32 \\
\hline \hline
\end{tabular}

Numbers in table are percentages.

Data for children with no missing value in any of the above activities.

\subsection{Cognitive and Non-Cognitive Skills}

The LSAC children were administered three cognitive skill tests depending on their age.

- Who am I? Test (Wave 1 only) The Who am I? is a direct child assessment measure that requires children to copy shapes (circle, triangle, cross, square, and diamond) and write numbers, letters, words and sentences. It is used for the children at ages 4 to 5 years to assess the general cognitive abilities needed for beginning school.

- Peabody Picture Vocabulary Test (Waves 1 and 2) A short form of the Peabody Picture Vocabulary Test (PPVT - III), a test designed

\footnotetext{
${ }^{11}$ In the data there is also information about Internet use. However, this is far less common than the activities in table 2. The full questionnaire is available at http://www.aifs.gov.au/ growingup/pubs/surveyinstruments/wave2.5/w2p5k-labelled.pdf
} 
to measure a child's knowledge of the meaning of spoken words and his or her receptive vocabulary. The Wave 1 and Wave 2 versions of the PPVT contain different, although overlapping, sets of items of appropriate difficulty for children aged 4-5 years and 6-7 years. A PPVT stimulus book with 40 plates of display pictures was used. The child is not required to define words but to show what they mean by pointing to (or saying the number of) a picture that best represents the meaning of the word.

- Matrix Reasoning Test (Wave 2 only) Children completed the Matrix Reasoning (MR) test from the Wechsler Intelligence Scale for Children, 4th edition (WISC-IV). This test of non-verbal intelligence presents the child with an incomplete set of pictures and requires them to select the picture that completes the set from 5 different options.

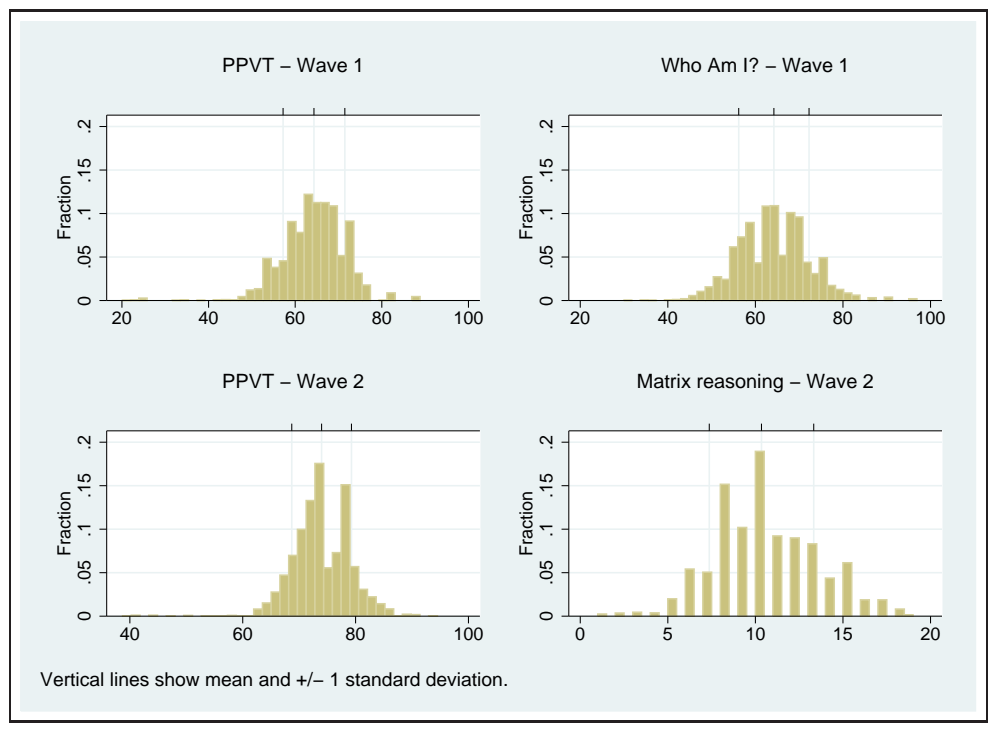

Figure 3: Cognitive Skills

Figure 3 shows the distribution of the cognitive test scores. Each distribution is quite symmetric. The matrix reasoning score has a different scale from the other tests. Later we standardize each test score to have mean zero and standard deviation 1 .

In the LSAC, non-Cognitive skills are measured through both parental and teacher assessment. In the two waves parents and teachers were asked 25 questions about children's behavior. All but two of the 25 questions did not change between the two waves. Answers to each question can take 3 values: 1 Not true; 2 Somewhat true; 3 Certainly true. However, teachers' answers are available only if the child went to school and the parents authorized the interviewer to 
go to the school. Because of the larger sample size and in order to avoid sample selection (in school) problems, in the remaining of the paper we only use parental assessment.

In order to construct some measures of non-cognitive skills we use iterated principal factor analysis and retain those factors with an eigenvalue larger than one. At each wave there are only 3 factors above this threshold. In table 3 we show the rotated loading factors. ${ }^{12}$ A possible interpretation of the 3 factors is the following: (1) Index of restlessness; (2) Index of good relationship with others; (3) Index of emotional problems.

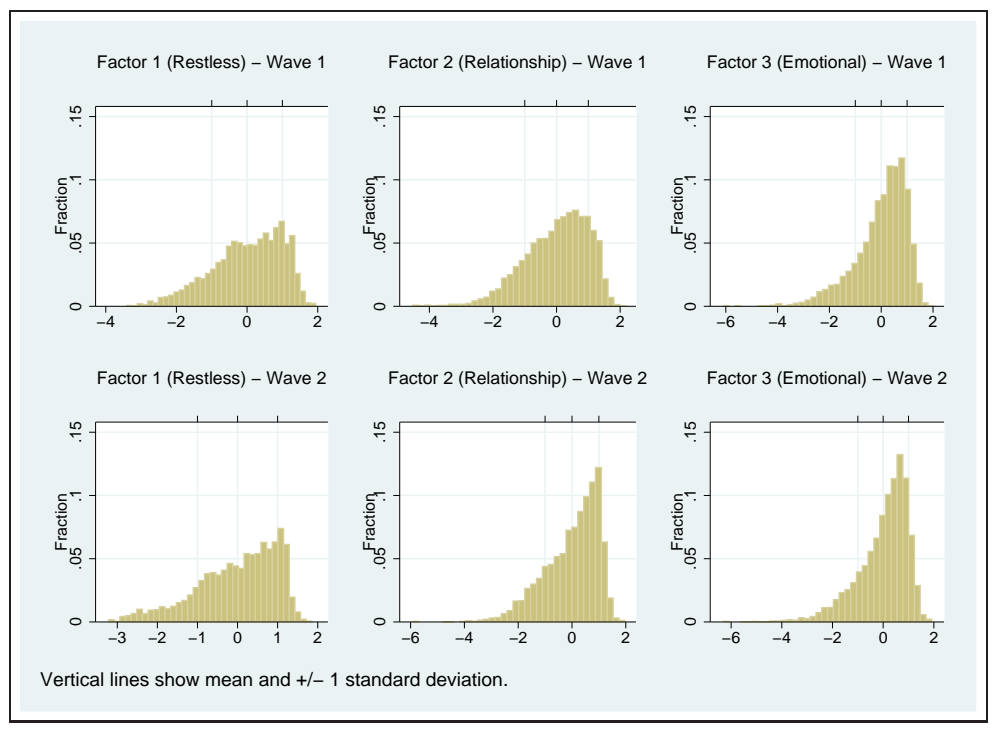

Figure 4: Non-Cognitive Skills

Each factor is standardized to have mean zero and standard deviation 1, and ordered such that a higher score corresponds to less behavioral problems, i.e. better non-cognitive skills. Figure 4 shows the distribution of the noncognitive factors derived from factor analysis. These factors have right-skewed distributions, that is the majority of children do not have behavioral problems. This is a feature of most of the 25 original questions.

\subsection{Other Variables of Interest}

The LSAC is a very rich data set. Plenty of information was collected about the child, his/her household, home and school environments. In table 4 we report basic statistics for a few variables. Children were on average 4 years and

\footnotetext{
${ }^{12}$ In the two cases where the question changed across waves, we show wave 2 question in brackets.
} 
Table 3: Non-Cognitive Skills Loading Factors

\begin{tabular}{|c|c|c|c|c|c|c|}
\hline & \multicolumn{3}{|c|}{ Wave 1} & \multicolumn{3}{|c|}{ Wave 2} \\
\hline & Factor1 & Factor2 & Factor3 & Factor1 & Factor2 & Factor3 \\
\hline Considerate of other peoples feelings & 0.2515 & 0.5423 & 0.0060 & 0.2125 & 0.6059 & 0.0431 \\
\hline Shares readily with other children & 0.1709 & 0.4254 & 0.0742 & 0.1262 & 0.4865 & 0.0749 \\
\hline Helpful if someone is hurt, upset or feeling ill & 0.0765 & 0.5449 & 0.0370 & 0.0273 & 0.5787 & 0.0282 \\
\hline Kind to younger children & 0.0954 & 0.4940 & 0.0682 & 0.0688 & 0.4972 & 0.0841 \\
\hline Often volunteers to help others & 0.0600 & 0.5351 & -0.0348 & 0.1023 & 0.5492 & -0.0799 \\
\hline Restless, overactive, cannot stay still for long & 0.7014 & 0.0796 & 0.0439 & 0.7144 & 0.0720 & 0.0852 \\
\hline Constantly fidgeting or squirming & 0.6503 & 0.0326 & 0.1061 & 0.7023 & 0.0498 & 0.1250 \\
\hline Easily distracted, concentration wan & 0.6076 & 0.1142 & 0.1008 & 0.6509 & 0.1175 & 0.1206 \\
\hline Thinks things out before acting & 0.2864 & 0.3790 & -0.0887 & 0.3799 & 0.3534 & -0.0422 \\
\hline Good atter & 0.4478 & 0.3237 & -0.0921 & 0.5302 & 0.3095 & -0.0100 \\
\hline ins of sickne & 0.1408 & -0.0160 & 0.2796 & 0.0720 & -0.0280 & 0.3482 \\
\hline ems worried & 0.0652 & -0.0403 & 0.5244 & 0.1230 & 0.0095 & 0.5852 \\
\hline Oftei & 0.1859 & & 0.4 & 0.1719 & 0.0985 & 0.4780 \\
\hline Nervous or clingy in new situations & 0.0750 & 0.0857 & 0.4087 & 0.0946 & 0.0509 & 0.3904 \\
\hline Many fears, easily scared & 0.1382 & 0.0638 & 0.5105 & 0.1342 & 0.0233 & 0.5369 \\
\hline Often 1 & 0.4547 & 0.1721 & 0.1839 & 0.3785 & 0.1901 & 0.2985 \\
\hline Generally well behaved, & 0.3823 & 0.1882 & 0.2645 & 0.2859 & 0.2388 & 0.2911 \\
\hline Often fights with other children or bullies them & 0.4433 & 0.1434 & 0.1963 & 0.3115 & 0.1471 & 0.2201 \\
\hline Often argumentative with adults (Often lies or & 0.3101 & 0.1668 & 02583 & 0.1760 & 0.0961 & 0.2134 \\
\hline Can be & 0.3983 & 0.4363 & 0.0056 & 0.3747 & 0.4661 & 0.0777 \\
\hline Rather solitary, tends to play alone & 0.0515 & 0.1097 & 0.3760 & 0.0843 & 0.1024 & 0.3884 \\
\hline Has at least one good friend & 0.1424 & 0.0338 & 0.3940 & 0.1947 & 0.0541 & 0.4070 \\
\hline Generally liked by other children & 0.1381 & 0.0118 & 0.4029 & 0.1251 & 0.0443 & 0.3881 \\
\hline Picked on or bullied by other child & 0.0256 & 0.3307 & 0.1466 & 0.0493 & 0.3003 & 0.2192 \\
\hline Gets on better with adults than with othe & 0.0502 & 0.4762 & 0.2235 & 0.1493 & 0.4508 & 0.2768 \\
\hline
\end{tabular}


9 months at wave 1 , and 6 years and 10 months at wave 2 . However there is a difference of 16 (19) months between the youngest and oldest child in wave 1 (wave 2). These children had on average $1 \frac{1}{2}$ siblings and in $95 \%$ of the case there were at most 3 siblings. The average mother was slightly younger than 30 years old at birth, and the average father slightly older than that. Most parents had some educational qualification beyond year 12 (high school). Father's income was substantially larger than mother's income, also due to a low fraction of mothers working full-time. The fraction of mothers working either full or part time rose between wave 1 and 2 .

\begin{tabular}{l|cc|cc}
\multicolumn{6}{c}{ Table 4: Other Variables of Interest } \\
\hline \hline & \multicolumn{3}{|c}{ Wave 1 } & \multicolumn{2}{c}{ Wave 2} \\
& Mean & SD & Mean & SD \\
\hline Child's Age (months) & 56.91 & 2.62 & 81.91 & 2.95 \\
Number of Siblings & 1.48 & 1.03 & 1.59 & 1.04 \\
Father Age (years) & 37.62 & 6.02 & 39.61 & 6.12 \\
Mother Age (years) & 34.81 & 5.23 & 36.90 & 5.26 \\
Father Higher Education & 0.75 & 0.43 & 0.77 & 0.42 \\
Mother Higher Education & 0.65 & 0.48 & 0.68 & 0.47 \\
Father Income (10 thous) & 5.36 & 3.82 & 6.44 & 5.20 \\
Mother Income (10 thous) & 2.27 & 2.03 & 2.81 & 2.83 \\
Mother Empl. Full-Time & 0.20 & 0.40 & 0.25 & 0.43 \\
Mother Empl. Part-Time & 0.38 & 0.48 & 0.41 & 0.49 \\
\hline \hline
\end{tabular}

\section{Results and Discussion}

In this section we provide estimates of the linear production functions in equations (2) and (4). Given the endogeneity problems discussed in section 3, and given that all estimators demand relatively strong assumptions, in what follows we report the parameters of interest of (2) and (4) using different estimators. All the test scores have been standardized to have mean zero and standard deviation 1. Computer time is measured as total weekly hours.

\subsection{Period 1 Estimation}

In table 5 we present the estimated effects of computer use on cognitive and non-cognitive skills. The first column (OLSa) illustrates the estimated impact when controlling for some measures of family, school and other media inputs such as weekly hours in child care, indoor and outdoor activities involving a family member, hours spent watching TV. ${ }^{13}$ Children using the computer more often score higher in the Peabody Picture Vocabulary and Who am I? tests. With regard to the non-cognitive scores, the Relationship index coefficient is

\footnotetext{
${ }^{13} \mathrm{~A}$ full list of the control variables used in this and later tables is available in the Appendix. Note that in table 5 media activities are given by the number of hours watching TV/DVD's while for wave 2 we also include hours playing with videogame consoles.
} 
positive and significant at $1 \%$ level, meaning that children using a computer are considered more sociable by their mothers.

Table 5: Production Function - Period 1

\begin{tabular}{l|cc|cc|cc|c}
\multicolumn{7}{|c}{ Table 5: Production Function - Period 1 } \\
\hline \hline \multirow{4}{*}{ PPV test } & OLSa & OLSb & IVa & DWH & Current & Future & $\bar{R}^{2} / \mathrm{N}$ \\
\hline \multirow{4}{*}{ WAI test } & $0.023^{* *}$ & $0.021^{* *}$ & $0.054^{* *}$ & 0.001 & $0.022^{* *}$ & -0.002 & 0.23 \\
& $(0.006)$ & $(0.006)$ & $(0.011)$ & - & $(0.006)$ & $(0.005)$ & 3990 \\
& $0.028^{* *}$ & $0.027^{* *}$ & $0.044^{* *}$ & 0.054 & $0.025^{* *}$ & 0.007 & 0.31 \\
& $(0.006)$ & $(0.005)$ & $(0.010)$ & - & $(0.005)$ & $(0.004)$ & 4396 \\
\hline Restless index & $0.012^{*}$ & 0.009 & $0.031^{* *}$ & 0.030 & 0.010 & -0.004 & 0.12 \\
Relationship index & $(0.005)$ & $(0.005)$ & $(0.011)$ & - & $(0.005)$ & $(0.004)$ & 4436 \\
& $0.015^{* *}$ & $0.018^{* *}$ & 0.022 & 0.713 & $0.021^{* *}$ & $-0.010^{*}$ & 0.06 \\
Emotional index & $(0.005)$ & $(0.005)$ & $(0.012)$ & - & $(0.005)$ & $(0.005)$ & 4436 \\
& 0.006 & -0.001 & 0.018 & 0.075 & 0.001 & -0.006 & 0.09 \\
& $(0.007)$ & $(0.006)$ & $(0.012)$ & - & $(0.006)$ & $(0.004)$ & 4436 \\
\hline \hline
\end{tabular}

Standard Errors in brackets. Stars indicate significance at $1 \%(* *)$ and $5 \%(*)$ level.

OLSa: control for type of school, child home and outdoor activities with family members, child extra activities such as sport and music classes, computer in school, home TV time, etc.

OLSb: like OLSa plus control for household demographics, parental education and financial situation, etc.

IVa: like OLSb plus instrument computer time with computer access.

DWH: p-value from a Durbin-Wu-Hausman endogeneity test

Future: like OLSb plus $C_{2}$ in addition to $C_{1}$.

In column OLSb we add a very rich set of household characteristics such as parental education, income and work status, number of siblings, State and Region of residence, etc. (Full list in Appendix). None of the additional controls is a direct family $(F I)$, school $(S I)$ or other media $(O M)$ input but we rather consider them as important determinants of these inputs. Since it is rare to observe all inputs, household characteristics are often used as proxies in similar studies. Some of these additional controls can also be viewed as proxies for the unobserved cognitive and non-cognitive endowment $\mu$. Overall the coefficients are smaller but with no large change. This result is reassuring and it suggests that our set of inputs is quite comprehensive.

To better understand the magnitude of the effect we compare the computer coefficient in column OLSb to those of TV/DVD and child care weekly hours (see table 15 in the Appendix for the coefficients of a subset of control variables). ${ }^{14}$ For the Peabody Picture Vocabulary, Who am I? and Relationship index scores, the TV/DVD coefficients are respectively, $-0.001,-0.008^{* *}$ and $0.007^{* *}$ of a standard deviation, i.e. smaller and of opposite sign to the computer ones. The child care coefficients are $-0.004,0.005^{*}$ and -0.000 of a standard deviation, again much smaller than the computer coefficients. Clearly endogeneity problems might bias these latter coefficients as much as the computer coefficient. However, unless the bias is large and possibly of different sign (i.e. computer

\footnotetext{
${ }^{14}$ Child care hours are given by the average weekly hours in school, kindergarten, pre-school or day care.
} 
coefficients are upward biased while TV/DVD and child care coefficients are downward biased) there is evidence that computer time is an important input in the production function.

Next we move to the IV estimator. Since we are not aware of any institutional change (laws or similar) that might affect $C_{t}$ our approach is to use computer access at home $\left(H C_{1}\right)$ to instrument $C_{1}$. In section 3.1 we discussed under what conditions this estimator is consistent. To satisfy the exclusion restriction we need computer access to be uncorrelated with unobserved inputs and the endowment. Given the large fraction of children with access to a home computer, we expect that, if anything, only a few parents owning a computer deny access to their children. Therefore it is unlikely that $H C_{1}$ is correlated with $\mu$. In table 13 we then compare households with and without a computer over a number of observable characteristics. Households with a computer are on average older, better educated, richer and more likely to have the mother employed. Our assumption is that conditional on these and the other controls included in OLSb, households with and without a computer do not differ over any other unobserved input of the production function and that $H C_{1} \perp \mu$. With regard to the rank condition, a first stage regression of $C_{1}$ on $H C_{1}$ and all other control variables used in OLSb show that $H C_{1}$ coefficient is positive and strongly significant (see table 14, Wave1/FSIVa column, in the appendix). By definition the $H C_{1}$ coefficient is simply equal to $E\left(C_{1} \mid X_{1}, H C_{1}=1\right)$. Back to table 5 , column IVa, we see that under the IV estimator the return to computer use becomes larger for all cognitive and non-cognitive scores. This result is consistent with attenuation bias caused by measurement error in $C_{1}$ while it is more difficult to judge the direction of potential omitted variable bias. Smart children might be more likely to use the computer for educational purposes and less likely to use it for entertainment but this is not given. At the same time smart children might prefer books to computers. It is also unclear whether non-cognitive skills and computer time would be positive or negatively correlated if anything. It is also possible that the ATT identified by the IV estimator is larger than the ATE. Column DWH shows the p-value from a Durbin-Wu-Hausman endogeneity test. There is evidence of endogeneity mainly for the PPVT test and to some extent for the Restlessness index while in the other cases the IV estimator is not much larger than the OLS one.

Finally, we run a robustness test by estimating the effect of $C_{2}$ on $T_{1}$. That is we run the OLSb model with the addition of $C_{2}$. As discussed in section 3.1 , conditional on $C_{1}$, future computer use $C_{2}$ should have no correlation with $T_{1}$ unless $C_{2}$ is a function of $\mu$ (skill endowments) and $U_{1}$ (unobserved inputs). Therefore we interpret the null hypothesis that the $C_{2}$ coefficient is equal to zero as a test of exogeneity conditional on our controls. If that fails then it is also likely that $E\left(v_{j 1}^{\prime} C_{1}\right) \neq 0$. The fifth (Current) and sixth (Future) columns of table 5 show respectively the $C_{1}$ and $C_{2}$ coefficients. Only in the case of the Relationship index the $C_{2}$ coefficient is statistically different from zero. However, the $C_{2}$ coefficient is negative. If this is just an omitted variable bias, 
then the true $\beta_{j 1}$ is actually larger and not smaller than the OLS estimates. ${ }^{15}$

The last column $\left(\bar{R}^{2} / \mathrm{N}\right)$ reports the adjusted $\bar{R}^{2}$ for the richest OLS regression (OLSb) and the sample size (N). The $\bar{R}^{2}$ is larger for the cognitive scores production function. Not reported, we also investigate whether the production function is linear in $C_{1}$ by introducing a quadratic term in the OLSb model. Its coefficient is negative but very small, suggesting that the production function is relatively linear in computer time.

To recap, both the OLS and IV estimator indicate that computer use in period 1 (age $4 / 5$ ) has a positive and statistically significant effect on the cognitive scores and on the Relationship index, with the OLS coefficients being relatively large compared to those of other inputs. The OLS estimator passes the robustness check (where we test for the effect of $C_{2}$ on $T_{j 1}$ ) for all scores but the Relationship index. However in this case, the negative coefficient suggests that omitted variables might actually bias the estimates downwards.

\subsection{Other Robustness Checks}

In this section we further test the robustness of our results. First, we experiment with alternative Instrumental Variables instead of computer access at home $\left(H C_{1}\right)$. Following a referee's suggestion, we use number of older siblings (conditional on number of siblings) together with 2001 Census data on internet use at work by males and females (at postcode level and conditional on census data on high school competition): three instruments in total. This IV specification is close to the one used by Beltran, Das, and Fairlie (2008). ${ }^{16}$ A first stage regression analysis excluding $H C_{1}$ reveals that these IV's are jointly significant with a p-value equal to 0.001 (see table 14, column Wave1/FSIVb). Column IVb in table 6 shows the IV estimates and compare it to the OLS estimate (column OLSb1). Note that column OLSb1 is not necessarily identical to column OLSb from table 5 since number of older siblings is now used as an IV and therefore it is no longer in the set of controls. The IV estimates become very large but unfortunately so do the standard errors. Only a few coefficient are significant at $5 \%$ level. If the exclusion restriction assumptions hold, this is further evidence of a positive causal effect. ${ }^{17}$

Next, we test the robustness of the OLS estimate to alternative coding of computer time use at Wave 1. Recall from our discussion in section 4.1 that at Wave 1 the number of hours were recorded in bands and not in continuous form. Therefore we had recoded number of hours in continuous form using

\footnotetext{
${ }^{15}$ We also run a model where we regress $T_{1}$ on $C_{2}$ using only those children who did not have access to a computer at the first wave. Thus the test of exogeneity relies on the sample of $14.83 \%$ of children who gained access between the two waves. The $C_{2}$ coefficients are close to those in table 5 .

${ }^{16}$ Intuitively, older siblings with computer skills might show the LSAC children how to use the computer (but at the same time they could crowd them out if there is only a computer in the house) and internet usage rates could work similarly or act as proxies for network effects.

${ }^{17}$ We also tried a specification where these three instruments were used together with computer access at home $\left(H C_{1}\right)$ rather then replacing it. This specification gave estimates that were very close and if anything slightly larger than those in column IVa, table 5.
} 
the median number of hours within each band from wave 2 and imputed that figure for wave 1 observations. It is possible that the results are sensitive to this coding. Columns OLSb2, OLSb3 and OLSb4 use respectively the mean, $25^{\text {th }}$ and $75^{\text {th }}$ percentile rather than the median. A comparison to Column OLSb in table 5 tells us that our results are robust to alternative coding.

Table 6: Other Robustness Checks - Period 1

\begin{tabular}{l|ccc|ccc}
\hline \hline & OLSb1 & IVb & DWH & OLSb2 & OLSb3 & OLSb4 \\
\hline PPV test & $0.022^{* *}$ & 0.119 & 0.221 & $0.020^{* *}$ & $0.022^{* *}$ & $0.019^{* *}$ \\
& $(0.006)$ & $(0.080)$ & - & $(0.005)$ & $(0.006)$ & $(0.005)$ \\
WAI test & $0.027^{* *}$ & $0.210^{*}$ & 0.025 & $0.026^{* *}$ & $0.029^{* *}$ & $0.024^{* *}$ \\
& $(0.005)$ & $(0.086)$ & - & $(0.005)$ & $(0.005)$ & $(0.004)$ \\
\hline Restless index & 0.009 & $0.221^{*}$ & 0.038 & 0.007 & 0.006 & 0.007 \\
& $(0.005)$ & $(0.112)$ & - & $(0.005)$ & $(0.006)$ & $(0.004)$ \\
Relationship index & $0.018^{* *}$ & 0.067 & 0.612 & $0.016^{* *}$ & $0.018^{* *}$ & $0.015^{* *}$ \\
& $(0.005)$ & $(0.097)$ & - & $(0.005)$ & $(0.006)$ & $(0.004)$ \\
Emotional index & -0.001 & 0.020 & 0.852 & -0.002 & -0.003 & -0.001 \\
& $(0.006)$ & $(0.109)$ & - & $(0.005)$ & $(0.006)$ & $(0.005)$ \\
\hline \hline
\end{tabular}

Standard Errors in brackets. Stars indicate significance at 1\% (**) and 5\% (*) level.

OLSb1: like OLSb but exclude number of older siblings from the set of control variables.

IVb: like OLSb1 plus instrument computer time with number of older siblings, fraction of males and females using internet at work (by postocode).

OLSb2, OLSb3, OLSb4: like OLSb but use respectively the mean, $25^{\text {th }}$ and $75^{\text {th }}$ percentile (rather than the median) number of hours within each band from wave 2 to construct a continuous measure of C1. See section 4.1.

\subsection{Period 2 Estimation}

In table 7 we show the parameter estimates for the period 2 production function (equation 4). For every test score function we report the $C_{2}$ (top) and $C_{1}$ (bottom) coefficients. The first three columns are obtained as in table 5 by controlling for family, school and other media inputs (OLSa), household characteristics (OLSb) and using computer ownership in both periods $H C_{2: 1}$ to instrument $C_{2: 1}$ (IVa). The only difference is that for all OLS and IV estimators we now control for characteristics in both periods $\left(X_{2: 1}\right)$ while in table 5 we controlled only for period $1\left(X_{1}\right)$. Conditional on $C_{1}$, current computer use $C_{2}$ does not have an effect on any cognitive or non-cognitive skill. However $C_{1}$ has a positive effect on both cognitive scores, with the IV estimator being larger than the OLS one. The DWH column shows the P value from a Durbin-Wu-Hausman endogeneity test: given the imprecision of the IV estimates there is evidence of endogeneity only for the Matrix Reasoning test score. For completeness, we also compute the IV estimates using the alternative set of instruments as in section $5.2(\mathrm{IVb})$. Like before, for the cognitive skills the $C_{1}$ coefficients become larger but also very imprecise. The following column $\left(\bar{R}^{2} / \mathrm{N}\right)$ reports the adjusted $\bar{R}^{2}$ for the richest OLSb regression and the sample size $(\mathrm{N})$. The Peabody Picture 
Table 7: Production Function - Period 2

\begin{tabular}{|c|c|c|c|c|c|c|c|c|c|}
\hline & & OLSa & $\mathrm{OLSb}$ & IVa & DWH & $\mathrm{IVb}$ & $\bar{R}^{2} / \mathrm{N}$ & VA & $\bar{R}^{2} / \mathrm{N}$ \\
\hline \multirow[t]{4}{*}{ PPV test } & $C_{2}$ & 0.006 & 0.004 & 0.000 & 0.848 & -0.066 & 0.21 & 0.005 & 0.34 \\
\hline & & $(0.004)$ & $(0.004)$ & $(0.017)$ & - & $(0.085)$ & 4409 & $(0.004)$ & 3960 \\
\hline & $C_{1}$ & $0.021 * *$ & $0.019 * *$ & 0.026 & - & 0.087 & - & $0.010^{*}$ & - \\
\hline & & $(0.004)$ & $(0.004)$ & $(0.013)$ & - & $(0.151)$ & - & $(0.004)$ & - \\
\hline \multirow[t]{4}{*}{ MR test } & $C_{2}$ & 0.008 & 0.007 & 0.020 & 0.011 & -0.009 & 0.09 & 0.005 & 0.16 \\
\hline & & $(0.004)$ & $(0.005)$ & $(0.016)$ & - & $(0.127)$ & 4413 & $(0.004)$ & 4347 \\
\hline & $C_{1}$ & $0.030 * *$ & $0.027 * *$ & $0.051 * *$ & - & 0.371 & - & $0.020 * *$ & - \\
\hline & & $(0.007)$ & $(0.007)$ & $(0.014)$ & - & $(0.194)$ & - & $(0.006)$ & - \\
\hline \multirow[t]{4}{*}{ Restless index } & $C_{2}$ & -0.003 & -0.003 & 0.012 & 0.179 & -0.091 & 0.13 & -0.001 & 0.41 \\
\hline & & $(0.005)$ & $(0.005)$ & $(0.018)$ & - & $(0.106)$ & 4179 & $(0.004)$ & 4159 \\
\hline & $C_{1}$ & -0.001 & 0.001 & 0.013 & - & -0.045 & - & -0.004 & - \\
\hline & & $(0.008)$ & $(0.008)$ & $(0.014)$ & - & $(0.208)$ & - & $(0.008)$ & - \\
\hline \multirow[t]{4}{*}{ Relationship index } & $C_{2}$ & -0.006 & -0.005 & -0.002 & 0.585 & 0.274 & 0.07 & -0.001 & 0.30 \\
\hline & & $(0.005)$ & $(0.005)$ & $(0.019)$ & - & $(0.180)$ & 4179 & $(0.004)$ & 4159 \\
\hline & $C_{1}$ & 0.006 & 0.007 & 0.017 & - & -0.494 & - & -0.003 & - \\
\hline & & $(0.005)$ & $(0.006)$ & $(0.016)$ & - & $(0.363)$ & - & $(0.006)$ & - \\
\hline \multirow[t]{4}{*}{ Emotional index } & $C_{2}$ & -0.002 & -0.006 & 0.018 & 0.331 & -0.252 & 0.10 & -0.003 & 0.28 \\
\hline & & $(0.005)$ & $(0.005)$ & $(0.019)$ & - & $(0.133)$ & 4179 & $(0.004)$ & 4159 \\
\hline & $C_{1}$ & 0.004 & -0.000 & -0.020 & - & 0.284 & - & 0.001 & - \\
\hline & & $(0.005)$ & $(0.005)$ & $(0.015)$ & - & $(0.277)$ & - & $(0.005)$ & - \\
\hline
\end{tabular}

Standard Errors in brackets. Stars indicate significance at $1 \%(* *)$ and $5 \%(*)$ level.

OLSa: control for type of school, child home and outdoor activities with family members, child extra activities such as sport and music classes, computer in school, home TV time, etc.

OLSb: like OLSa plus control for household demographics, parental education and financial situation, etc.

IVa: like OLSb plus instrument computer time with computer access.

IVb: like OLSb but exclude number of older siblings from the set of control variables and instrument computer time with number of older siblings, fraction of males and females using internet at work (by postocode).

VA: like OLSb plus lagged score on the right hand side.

Vocabulary function is the one with the largest $\bar{R}^{2} .{ }^{18}$

We then estimate the production function using the Value Added estimator (VA column). In section 3.2 we discussed the conditions under which this estimator is consistent. The estimates are obtained after augmenting the right hand side of each production function with the period 1 test score. Most of the $C_{2}$ coefficients drop. The $C_{1}$ coefficients drop too, but this is expected since we are including the lagged score on the right hand side (see section 3.2, footnote 8). As we would expect the $\bar{R}^{2}$ of the Value Added model is larger than the OLS estimator since the lagged score might be capturing the effect of unobserved innate abilities or past unobserved inputs. The sample size $\mathrm{N}$ is instead smaller since we only include those children for whom scores are available in both periods.

We do not include the First Difference estimator mainly because the wave 1

\footnotetext{
${ }^{18}$ To account for selection issues originating from the new pool of children gaining access between the two waves, we also compute the OLSb estimator for those children with computer access at both waves only. The $C_{1}$ coefficients become slightly smaller but remain statistically significant at $1 \%$ confidence level.
} 
computer hours were originally coded in bands. While it is already known that the First Difference estimator can exacerbate measurement error problems, in our case a $\Delta C$ variable created using our imputed continuous $C_{1}$ would generate even more measurement error. If instead we were to code both $C_{2}$ and $C_{1}$ in bands, we would loose all the children that did not change band between the two waves, roughly half of the sample.

As in section 5.1 we also test for non-linearities in computer time but again we find little evidence in this direction.

To summarize, the results from period 2 suggest that computer use at young ages has a long lasting effect on cognitive skills, while current (age 7) use has no strong effect. It is possible that computer activities around age 5 are more educational (perhaps there is more parental control) or that, as Cunha, Heckman, and Lochner (2006) suggest, cognitive skills are most malleable only at young ages. Per contra, neither $C_{2}$ nor $C_{1}$ show an effect on the non-cognitive skill indexes. These results are consistent across the OLS, IV and Value Added estimators.

\subsection{Weekday vs Weekend}

We now try to exploit the information in our data by separating $C_{t}$ into weekday $\left(C_{t}^{w d}\right)$ and weekend $\left(C_{t}^{w e}\right)$ computer hours: $C_{t}=C_{t}^{w d}+C_{t}^{w e}$. The $C_{t}$ coefficient is expected to lie in between the $C_{t}^{w d}$ and $C_{t}^{w e}$ ones. ${ }^{19}$ In table 8 we show the results. Once again we report the OLSb estimator, column $\operatorname{OLSb}\left(T_{t}\right)$, and the value added estimator, column $\mathrm{VA}\left(T_{t}\right)$. We also attempted to evaluate the IV estimator by augmenting the first stage regression with the interactions between computer access on one side and number of siblings, number of older siblings, father's and mother's income on the other, while also including all these variables in their linear form (not-reported). These additional IVs are needed given the separation of $C_{t}$ into $C_{t}^{w d}$ and $C_{t}^{w e}$. However the IV estimates are very imprecise and therefore omitted.

Starting with the cognitive skills, we see that what is important is computer use during the weekend, with coefficients sensibly larger than those in tables 5 and 7 . For the Matrix Reasoning test, $C_{2}^{w e}$ now has a statistically significant effect, even when using the VA estimator, while in table $7 C_{2}$ had a negligible effect. This is because the $C_{2}$ coefficient is a weighted sum of the $C_{2}^{w d}$ and $C_{2}^{w e}$ ones. But why is it weekend computer time that matters? On the one hand since parents are more likely to be home (i.e. not working) during the weekend, they might be spending time with their children using educational software or other programs. On the other hand, it is possible that computer time during the weekday displaces other positive inputs of the cognitive production function, such as homework or other educational assignments, producing a zero sum effect, while during the weekend computer time displaces activities that are not cognitive skill enhancing, such that computer time has a net positive effect.

\footnotetext{
${ }^{19}$ This is true if $\operatorname{Cov}\left(C_{t}^{w d}, C_{t}^{w e}\right)>0$, which is the case in our sample.
} 
For the non-cognitive skills, and in particular the Relationship index, it is weekday time that is important at wave 1 , while again there is no effect at wave 2. In the absence of information on computer activities and displaced activities, we do not have a clear intuition for this result.

\subsection{Heterogeneity in the Production Function}

In this section we investigate whether the production function parameters are heterogeneous. In particular we look at differences based on the children's sex and on their mothers's education and labor market status. Tables 9 and 10 illustrates the results for the two periods. For clarity we only report the OLSb estimator and the Relationship index coefficients among the non-cognitive skills. Given the results in section 5.4, we also exclude the $C_{t}^{w d}$ coefficients for the cognitive skills and the $C_{t}^{w e}$ coefficient for the Relationship index. Most of the coefficients are not significantly different across groups though some patterns emerge.

For most scores, the impact of computer use is almost always larger for girls. There is some evidence that among teenagers, boys and girls use the computer differently, with boys spending more time playing games and girls using it more for emailing and chatting (see Subrahmanyam, Kraut, Greenfield, and Gross (2000)), though we do not know whether these differences in usage apply also to younger children. There is also evidence that boys and girls learn differently (see Gurian (2002)). However, a more complete investigation of these differences between boys and girls is beyond the scope of this paper.

Next, we divide our sample in three groups based on mothers's education: below year 11, year 11 or 12 (completed high school), higher education. As we mentioned in the introduction, computer time might matter depending on the content and/or depending on the activities that are displaced by it. On the one hand, if it is content that matters, than children with better educated parents should have a higher return to computer time. This would be the case if better educated parents are more aware of which computer usages are educational or if they are more computer savvy themselves, and can teach their children how to use computers. On the other hand, if the effect comes mainly through the displaced activities, than children with low educated parents might have the highest return, since computer time might be more educational than time with parents. For instance, Bernal and Keane (2009) find that the effect of child care is positive mainly for children with low educated parents. The authors point at the displacement effect to explain this result. Tables 9 and 10 suggest that both channels might be in place. For the cognitive scores the effect of computer time is usually largest for the low educated, followed by the high educated parents groups. This is not true for Relationship index and in fact there is no strong reason for the above intuition to apply to non-cognitive skills too.

Finally, we also test whether there is heterogeneity depending on the mother's working status. We distinguish between full-time, part-time and not working, the latter including mothers looking for a job, in maternity leave or out of the labor force. One way to explain a stronger return for weekend versus weekday 
time is to assume that parents can guide computer use better during the weekend, since they are more likely to be home and have time for the child. If this is true, than we would expect the difference between weekend and weekday use to be largest among children with working mothers. For the cognitive skills, the last three columns of tables 9 and 10 indeed indicate that the difference between the weekend and weekday returns is larger for those children with mothers working full or part time. This result is also in line with the hypothesis that content matters. For the Relationship index, there is also evidence that $C_{1}$ weekday time has a stronger effect for those children with mothers working full or part time.

\subsection{Multimedia}

Lastly, in this section we compare the return to computer, television and video games time. In table 11 we present the results for the period 1 production function. The first columns correspond to the OLS return and is therefore identical to column OLSb in table 5. The second column (IV) differs from the one in table 5 because we now also instrument TV time with number of televisions in the house. That is we regress the scores on computer and TV time in the same regression and, for the IV estimates, instrument computer and TV time respectively with computer access and number of TV's in the house. The last two columns show the return to TV time.

Testing whether computer and TV time have a different return is interesting in light of our previous discussion. Both computers and TV are media devices, both will have an effect on children's skills depending on their content, on the activities they displace and on their intellectual stimulation. From table 11 it appears that computer and TV time have a very different effect. TV time has a statistically significant negative return on almost all scores, cognitive and noncognitive. For both computer and TV time, the IV estimates are usually larger (in absolute value) than the OLS ones. Note that our result of pre-school TV time having a negative effect on development is in contrast with the findings of Gentzkow and Shapiro (2008). However, they use 1950's data for the US in order to exploit heterogeneity in the timing of television's introduction as a source of identification. As they admit, it is possible that the type and variety of television content has changed over time in such a way as to alter its effects on cognitive development. It is also likely that alternatives displaced by TV time have changed over time, and this could produce different results.

In table 12 we repeat the analysis for the period 2 production function. Now we also include, in the same regression, video game time, that is time spent playing games using consoles such as Xbox, Nintendo and Playstation. We only include period 2 media time and do not separate between current and lagged like we did in table 7 . This is because we do not observe video games time in period 1 but we want to keep the estimates comparable across the three media devices. ${ }^{20}$

\footnotetext{
${ }^{20}$ We do not include lagged computer, TV and video game time but we do include current and lagged measures for all other control variables.
} 
The IV estimates are obtained instrumenting computer, TV and video games time with computer access, TV in child's bedroom (yes/no) and video game console access. It is unfortunate that in period 2 we do not observe number of televisions in the house. It is rather unlikely that the presence of a TV in the child's bedroom, as much as access to video game console, are uncorrelated with the child's characteristics. Nevertheless we still include the IV estimates for completeness. We also show the Value Added estimates obtained by including the lagged score on the right hand side. Television still has a negative effect for most of the scores, no matter which estimator is used, though the Value Added estimates are generally smaller. The effect of spending time playing with video games is also mostly negative even though only for the Peabody Picture Vocabulary score this effect is statistically significant.

\section{Conclusions}

The objective of this paper is to investigate the effect of using a home computer on children's cognitive and non-cognitive development. Data show that in OECD countries $70 \%$ or more of the households have a computer at home. Our Australian data also show that in families with young children this percentage can go up to almost $90 \%$ and that children do make use of computers even at very young ages. However not much is known about the effect of computers. Computers are a relatively new input in the skill production function having entered the average household mainly in the last fifteen years. Previous research in economics has focused on the effect of home computers on high school graduation (positive effect) or on the effect of computer use in school, the latter often specific to a particular computer-assisted learning program (mixed findings). Psychologists instead have already completed some studies on the effect of home computer usage but data is mainly available for teenagers and some of these studies do not deal with the endogeneity of computer time.

In our work we use data from an Australian cohort born in 1999/2000, with information collected in 2004 and 2006. The advantage of using this sample is twofold. These children are very young and data is recent. The latter is an important characteristic since computers, software, internet availability and parental computer skills all have changed sensibly in the last two decades. We are not aware of any similar study.

For cognitive skills, our results indicate that computer time has a positive effect. The effect is long-lasting with early computer use showing an impact on test scores even two years later. This positive effect originates mainly from computer time during the weekend, is larger for girls, for children with low or highly educated parents and for children with working parents. The effect is large relatively to those of other inputs that have received more attention in the literature, such as child care, and is not shared by other media devices, such as television and video games which instead show a negative effect.

In the introduction we pointed a three channels through which computer use might impact child development: content, displaced activities and intellectual stimulation. The pattern of results does not suggest an unequivocally dominant 
channel. On the one hand, a number of facts could be interpreted as evidence that parental presence, which is likely to drive content, matters: the difference between the Wave 1 (positive and significant) and Wave 2 (essentially zero) coefficients, the larger effect during the weekend and for children with working parents. The negative returns to television and video games use and the slightly larger effect for girls (if girls are less likely to play games) also indicate that content is important. On the other hand, a larger effect for children with low educated parents is less consistent with the idea that content is all that matters and rather points in the direction of displaced activities. Most likely both channels are important. It is hard to infer whether intellectual stimulation is also working. The result that video games use is not beneficial to cognitive skills, even though playing games is probably stimulating as the children try to "crack" the game in order to succeed, would exclude this channel. However one could also argue that educational software can be stimulating in a different way than video games are, a way presumably more effective for measures of cognitive skills which capture verbal and math abilities.

For the non-cognitive skills the evidence is more mixed. For two out of three indicators of non-cognitive skills, the Restless and the Emotional index, we do not find any link with computer time. For the Relationship index, which assesses the child's propensity to behave in a way that is considerate and helpful to others, we find a positive effect for children aged between 4 and 5 years. This effect originates mainly from computer time during the weekday, is larger for girls, and for children with highly educated and working parents. However two years later the effect vanishes. It is harder to interpret the positive effect on the Relationship index. If anything, we were expecting a negative effect, with computer time use displacing other social activities. It is also possible that this is just a spurious correlation. Since the non-cognitive skills indexes are derived from parental assessment there could be some unobservable driving both parental assessment and computer time. However, we also find that future computer time has a negative effect on the current Relationship index, meaning that the bias might be attenuating the effect rather then reinforcing it.

We test the robustness of all our results by comparing OLS, IV and Value Added estimators. Generally, the IV estimates are larger and the Value Added estimates lower than the OLS ones. However the pattern of results is consistent.

Clearly, a more exhaustive investigation of the mechanisms behind the computer effect would demand information on actual computer activities, which are not available for the first two waves of our data. We do have some information a later wave, but then we lack measures of cognitive and non-cognitive skills. We refrain from using these later data as an indicator of early computer activities. First because of poor quality of these data and second because we find unlikely that computer activities at age 8 and 9 are a good proxy of activities at age 5 . This is an area for future research. 
Table 8: Production Function - Weekday vs Weekend

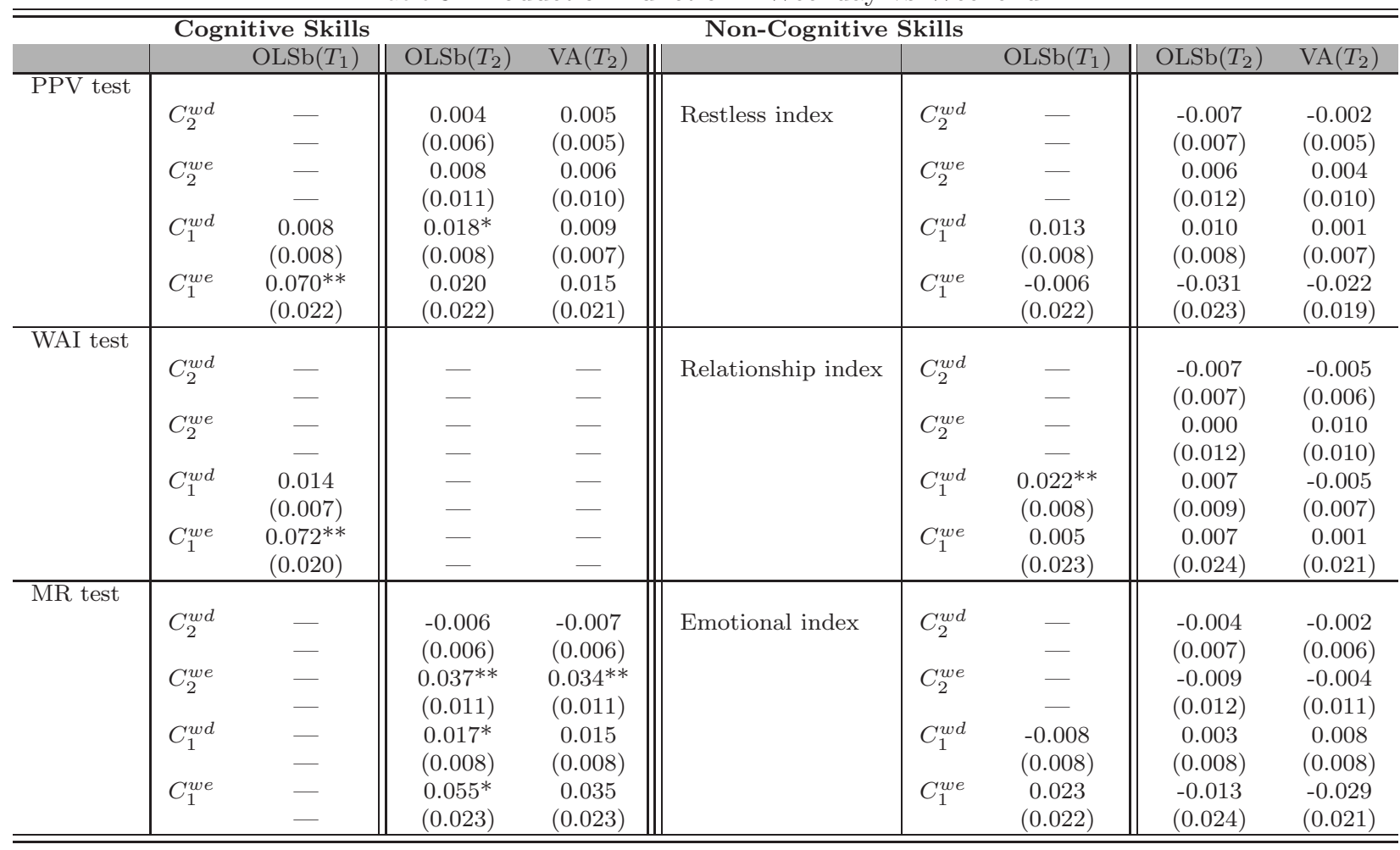

Standard Errors in brackets. Stars indicate significance at 1\% (**) and 5\% (*) level. 
Table 9: Heterogeneity in the Production Function - Period 1

\begin{tabular}{|c|c|c|c|c|c|c|c|c|c|}
\hline \multirow{4}{*}{$\overline{P P V \text { test }}$} & & Boys & Girls & M low Edu & $\bar{M}$ mid Edu & M high Edu & M work FT & M work PT & M not Wkg \\
\hline & & & & & & & & & \\
\hline & $C_{1}^{w e}$ & $\begin{array}{c}0.036 \\
(0.029)\end{array}$ & $\begin{array}{c}0.115^{* *} \\
(0.036)\end{array}$ & $\begin{array}{c}0.089 \\
(0.070)\end{array}$ & $\begin{array}{c}0.038 \\
(0.054)\end{array}$ & $\begin{array}{c}0.068^{*} \\
(0.027)\end{array}$ & $\begin{array}{c}0.078 \\
(0.043)\end{array}$ & $\begin{array}{l}0.080^{*} \\
(0.035)\end{array}$ & $\begin{array}{c}0.067 \\
0.042)\end{array}$ \\
\hline & $\mathrm{N}$ & 2031 & 1959 & 542 & 856 & 2571 & 793 & 1499 & 1677 \\
\hline \multirow{8}{*}{ Relationship index } & & & & & & & & & \\
\hline & $C_{1}^{\text {we }}$ & $0.068^{* *}$ & 0.091 ** & $0.147^{* *}$ & -0.002 & $0.059^{*}$ & 0.068 & $0.096^{* *}$ & 0.038 \\
\hline & & $(0.026)$ & $(0.032)$ & $(0.055)$ & $(0.050)$ & $(0.025)$ & $(0.043)$ & $(0.031)$ & $(0.035)$ \\
\hline & $\mathrm{N}$ & 2236 & 2160 & 597 & 936 & 2832 & 878 & 1647 & 1837 \\
\hline & & & & & & & & & \\
\hline & $C_{1}^{w d}$ & 0.019 & $0.034^{*}$ & 0.026 & 0.037 & 0.020 & $0.050^{* *}$ & $0.032^{*}$ & -0.004 \\
\hline & & (0.011) & $(0.014)$ & & $(0.022)$ & $(0.012)$ & $(0.018)$ & $(0.013)$ & $(0.016)$ \\
\hline & $\mathrm{N}$ & 2255 & 2181 & 602 & 946 & 2857 & 887 & 1665 & 1850 \\
\hline
\end{tabular}

Standard Errors in brackets. Stars indicate significance at $1 \%\left({ }^{* *}\right)$ and $5 \%\left({ }^{*}\right)$ level. 
Table 10: Heterogeneity in the Production Function - Period 2

\begin{tabular}{|c|c|c|c|c|c|c|c|c|c|}
\hline & & Boys & Girls & M low Edu & M mid Edu & M high Edu & M work FT & M work PT & M not Wkg \\
\hline \multicolumn{10}{|l|}{ PPV test } \\
\hline & $C_{2}^{w e}$ & 0.011 & -0.000 & -0.043 & 0.013 & 0.002 & 0.009 & -0.001 & -0.002 \\
\hline & $C_{1}^{w e}$ & $\begin{array}{l}(0.014) \\
-0.002\end{array}$ & $\begin{array}{c}(0.018) \\
0.041\end{array}$ & $\begin{array}{c}(0.039) \\
0.159\end{array}$ & $\begin{array}{l}(0.028) \\
-0.053\end{array}$ & $\begin{array}{c}(0.013) \\
0.012\end{array}$ & $\begin{array}{c}(0.025) \\
0.026\end{array}$ & $\begin{array}{c}(0.017) \\
0.057\end{array}$ & $\begin{array}{l}(0.020) \\
-0.012\end{array}$ \\
\hline & & $\begin{array}{l}-0.002 \\
(0.029)\end{array}$ & $(0.036)$ & $(0.082)$ & $(0.062)$ & $(0.027)$ & $(0.045)$ & $(0.035)$ & $(0.047)$ \\
\hline & $\mathrm{N}$ & 2248 & 2161 & 546 & 834 & 2988 & 1094 & 1800 & 1477 \\
\hline \multicolumn{10}{|l|}{ MR test } \\
\hline & $C_{2}^{w e}$ & $0.044^{* *}$ & 0.037 & 0.019 & 0.045 & $0.034^{*}$ & 0.053 & $0.048^{*}$ & -0.005 \\
\hline & & $(0.015)$ & $(0.019)$ & $(0.036)$ & $(0.030)$ & (0.015) & $(0.028)$ & (0.019) & $(0.021)$ \\
\hline & $C_{1}^{w e}$ & 0.030 & $0.098^{*}$ & $0.196^{*}$ & -0.083 & 0.039 & 0.075 & $0.110^{* *}$ & 0.031 \\
\hline & & $(0.032)$ & $(0.038)$ & $(0.079)$ & $(0.067)$ & $(0.030)$ & (0.049) & (0.039) & $(0.048)$ \\
\hline & $\mathrm{N}$ & 2248 & 2165 & 550 & 835 & 2987 & 1094 & 1800 & 1481 \\
\hline \multicolumn{10}{|l|}{ Relationship index } \\
\hline & $C_{2}^{w d}$ & -0.005 & -0.006 & 0.026 & $-0.062^{*}$ & -0.005 & 0.017 & -0.009 & -0.018 \\
\hline & & $(0.012)$ & $(0.009)$ & $(0.020)$ & $(0.024)$ & (0.009) & (0.018) & (0.009) & $(0.016)$ \\
\hline & $C_{1}^{w d}$ & 0.002 & 0.020 & -0.038 & $0.056^{*}$ & 0.021 & 0.011 & 0.000 & 0.048 \\
\hline & & $(0.012)$ & $(0.014)$ & $(0.020)$ & $(0.027)$ & $(0.013)$ & $(0.017)$ & $(0.013)$ & $(0.025)$ \\
\hline & $\mathrm{N}$ & 2124 & 2055 & 514 & 797 & 2829 & 1054 & 1725 & 1365 \\
\hline
\end{tabular}

Standard Errors in brackets. Stars indicate significance at $1 \%\left({ }^{* *}\right)$ and $5 \%\left({ }^{*}\right)$ level. 
Table 11: Multimedia Production Function - Period 1

\begin{tabular}{l|cc|cc}
\hline \hline & \multicolumn{2}{|c}{ PC } & \multicolumn{2}{c}{ TV } \\
& OLSb & IV & OLSb & IV \\
\hline PPV test & $0.021^{* *}$ & $0.054^{* *}$ & -0.002 & $-0.054^{* *}$ \\
& $(0.006)$ & $(0.011)$ & $(0.002)$ & $(0.018)$ \\
WAI test & $0.027^{* *}$ & $0.043^{* *}$ & $-0.008^{* *}$ & $-0.041^{* *}$ \\
& $(0.006)$ & $(0.010)$ & $(0.002)$ & $(0.015)$ \\
\hline Restless index & 0.009 & $0.030^{* *}$ & $-0.016^{* *}$ & $-0.036^{*}$ \\
& $(0.005)$ & $(0.011)$ & $(0.003)$ & $(0.017)$ \\
Relationship index & $0.018^{* *}$ & 0.022 & $-0.007^{* *}$ & 0.014 \\
& $(0.005)$ & $(0.012)$ & $(0.003)$ & $(0.017)$ \\
Emotional index & -0.001 & 0.018 & $-0.013^{* *}$ & -0.016 \\
& $(0.006)$ & $(0.011)$ & $(0.003)$ & $(0.017)$ \\
\hline \hline
\end{tabular}

Standard Errors in brackets. Stars indicate significance at $1 \%$ $(* *)$ and $5 \%(*)$ level.

IV: instrument computer time with computer access and TV time with number of televisions in the house.

Table 12: Multimedia Production Function - Period 2

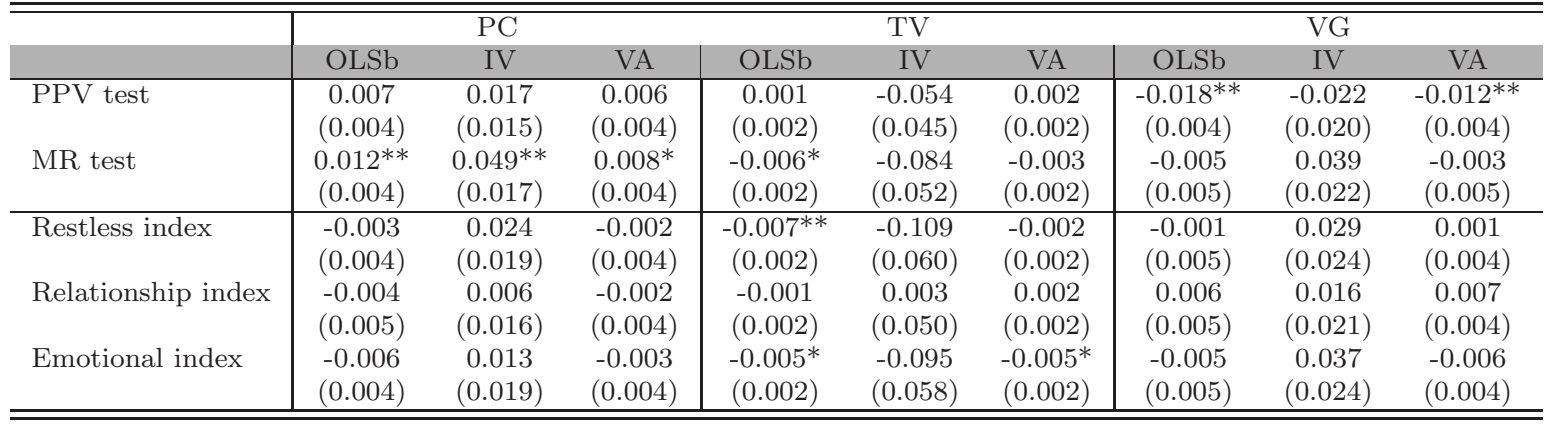

Standard Errors in brackets. Stars indicate significance at $1 \%(* *)$ and $5 \%(*)$ level.

IV: instrument computer time with computer access, TV time with television in child's bedroom (binary) and video games time with video game console access. 


\section{Appendix}

Control variables used in the Results section.

We use the abbreviations 's.c.' (study child), and 'n.' (number).

- OLSa:

FI : family member home activities with the s.c. in the last week (read to s.c. from a book; told s.c. a story not from a book; drawn pictures or did other art activities with s.c.; played music, sang songs, danced or did other musical activities with s.c.; played with toys or games indoors; involved child in everyday activities at home, such as cooking or caring for pets; played a game outdoors or exercised together like walking, swimming, cycling); family member outdoor activities with the s.c. in the last month (gone to a movie; gone to a playground or a swimming pool; gone to sporting event in which child was not a player; gone to a live performance for children; attended a school or cultural event; attended a religious service; visited a library); s.c. regularly spoken to in a language other than English; s.c. regularly attended special or extra cost activities that are not part of his/her normal child care, pre-school or school activities in the last 6 months? (swimming; gymnastics/kindergym; team sport; musical instruments or singing; dance; other).

$S I$ : type of school attended by the s.c. (adjusted by age); grade or year level in school; does child go to a school, kindergarten, pre-school or a day care centre? (wave 1); n. of hours on average per week s.c. goes to (school/ kindergarten/ pre-school/ day care) (wave 1); n. of different schools attended since beginning fulltime schooling (wave 2); computer in school (room has use of a computer; how often do the children have access to the computer).

$O M$ : TV hours; video game hours (wave 2).

- OLSb: OLSa controls + age (child); state of residence; region of residence; remoteness Area classification; age (parents); s.c. relationship to parents (biological or not); n. of people in home; grandmother in home; grandfather in home; $n$. of siblings; n. of older siblings; $n$. of same age siblings; $n$. of brothers; $n$. of sisters; $n$. of younger brother; $n$. of younger sisters; s.c. has a step- or half-sibling in home; s.c. has an adopted sibling in home; s.c. has a foster sibling in home; parental education; parental work status; parent ever work 6pm or overnight; parent ever work Saturdays or Sundays; financial problems in the last 12 months (could not pay gas, electricity or telephone bills on time; could not pay the mortgage or rent payments on time; went without meals; were unable to heat or cool your home; pawned or sold something because needed cash; sought assistance from a welfare or community organization); parents' annual income; language parents first spoke as a child; country grandparents were born; $\%$ of people aged 0 to 4 in postcode from census; \% of people aged 0 to 9 in postcode from census; $\%$ of people aged 0 to 17 in postcode from census; \% of people who have completed Year 12 in postcode from census; \% of Australian born people in postcode from census. 
Instrumental Variable

Table 13: Comparing households with and without a home computer

\begin{tabular}{|c|c|c|}
\hline & Wave 1 & Wave 2 \\
\hline Child's Age (months) & 0.011 & -0.008 \\
\hline Number of Siblings & 0.028 & -0.091 \\
\hline Father Age (years) & $0.768^{* *}$ & $0.782^{*}$ \\
\hline Mother Age (years) & $1.790 * *$ & $1.815^{* *}$ \\
\hline Father Higher Education & $0.084^{* *}$ & $0.076^{* *}$ \\
\hline Mother Higher Education & $0.143^{* *}$ & $0.144^{* *}$ \\
\hline Father Income (10 thous) & $1.120^{* *}$ & $1.547^{* *}$ \\
\hline Mother Income (10 thous) & $0.211^{* *}$ & $0.480^{* *}$ \\
\hline
\end{tabular}

Numbers in table are $E\left(X_{t} \mid H C_{t}=1\right)-E\left(X_{t} \mid H C_{t}=0\right)$.

$H C_{t}=1$ : household with home computer. $\quad H C_{t}=0$ : household without home computer.

Table 14: First Stage regression

\begin{tabular}{|c|c|c|c|c|c|c|}
\hline & \multicolumn{2}{|c|}{$\begin{array}{c}\text { Wave } 1 \\
C_{1}\end{array}$} & \multicolumn{4}{|c|}{ Wave 2} \\
\hline & FSIVa & FSIVb & FSIVa & FSIVb & FSIVa & FSIVb \\
\hline Computer Access (CA) @ Wave 2 & - & - & $\begin{array}{c}3.210^{* *} \\
(0.115)\end{array}$ & - & $\begin{array}{c}0.439^{* *} \\
(0.095)\end{array}$ & - \\
\hline Computer Access (CA) @ Wave 1 & $\begin{array}{c}3.214^{* *} \\
(0.081)\end{array}$ & - & $\begin{array}{c}0.729 * * \\
(0.136)\end{array}$ & - & $\begin{array}{l}3.111^{* *} \\
(0.086)\end{array}$ & - \\
\hline Number of Siblings@ Wave 2 & - & - & $\begin{array}{l}-0.283 \\
(0.245)\end{array}$ & $\begin{array}{c}-0.425 \\
(0.273)\end{array}$ & $\begin{array}{c}0.040 \\
(0.182)\end{array}$ & $\begin{array}{l}-0.152 \\
(0.219)\end{array}$ \\
\hline Number of Siblings@ Wave 1 & $\begin{array}{c}-0.234 \\
(0.152)\end{array}$ & $\begin{array}{c}-0.347^{*} \\
(0.165)\end{array}$ & $\begin{array}{c}0.068 \\
(0.311)\end{array}$ & $\begin{array}{c}0.695 \\
(0.429)\end{array}$ & $\begin{array}{l}-0.168 \\
(0.221)\end{array}$ & $\begin{array}{c}-0.133 \\
(0.257)\end{array}$ \\
\hline Number of Older Siblings @ Wave 2 & - & - & $\begin{array}{c}0.297 \\
(0.324)\end{array}$ & $\begin{array}{c}0.362 \\
(0.344)\end{array}$ & $\begin{array}{c}-0.235 \\
(0.339)\end{array}$ & $\begin{array}{c}-0.037 \\
(0.368)\end{array}$ \\
\hline Number of Older Siblings @ Wave 1 & $\begin{array}{c}0.202 \\
(0.148)\end{array}$ & $\begin{array}{c}0.510^{* *} \\
(0.142)\end{array}$ & $\begin{array}{c}0.110 \\
(0.362)\end{array}$ & $\begin{array}{c}-0.359 \\
(0.470)\end{array}$ & $\begin{array}{c}0.376 \\
(0.379)\end{array}$ & $\begin{array}{c}0.488 \\
(0.411)\end{array}$ \\
\hline$\%$ of males using internet at work (by postcode) & - & $\begin{array}{c}-0.044 \\
(0.023)\end{array}$ & - & $\begin{array}{c}-0.105^{* *} \\
(0.033)\end{array}$ & - & $\begin{array}{c}-0.028 \\
(0.025)\end{array}$ \\
\hline$\%$ of females using internet at work (by postcode) & - & $\begin{array}{c}0.025 \\
(0.019) \\
\end{array}$ & - & $\begin{array}{c}0.111^{* *} \\
(0.032)\end{array}$ & - & $\begin{array}{c}0.028 \\
(0.026) \\
\end{array}$ \\
\hline$R^{2}$ & 0.21 & 0.02 & 0.11 & 0.02 & 0.20 & 0.026 \\
\hline Ftest (IV's) & 1593.11 & 405.32 & 538.662 & 3.81 & 655.86 & 2.81 \\
\hline Ftest P-value (IV's) & 0.000 & 0.001 & 0.000 & 0.004 & 0.000 & 0.024 \\
\hline
\end{tabular}

FSIVa: include all the controls in OLSb. FSIVb: include all the controls in OLSb1. 
Estimated coefficients not reported in main tables.

Table 15: Production Function - Period 1 - OLSb specification

\begin{tabular}{|c|c|c|c|c|c|}
\hline & \multicolumn{2}{|c|}{ Cognitive } & \multicolumn{3}{|c|}{ Non Cognitive } \\
\hline & PPV test & WAI test & $\begin{array}{l}\text { Restless } \\
\text { Index }\end{array}$ & $\begin{array}{l}\text { Relations. } \\
\text { Index }\end{array}$ & $\begin{array}{l}\text { Emotiona } \\
\text { Index }\end{array}$ \\
\hline$C_{1}$ & $\begin{array}{l}0.021^{* *} \\
(0.006)\end{array}$ & $\begin{array}{l}0.027^{* *} \\
(0.005)\end{array}$ & $\begin{array}{l}0.009 \\
(0.005)\end{array}$ & $\begin{array}{l}0.018^{* *} \\
(0.005)\end{array}$ & $\begin{array}{l}-0.001 \\
(0.006)\end{array}$ \\
\hline TV/DVD time & $\begin{array}{l}-0.001 \\
(0.003)\end{array}$ & $\begin{array}{l}-0.008^{* *} \\
(0.002)\end{array}$ & $\begin{array}{l}-0.016^{* *} \\
(0.003)\end{array}$ & $\begin{array}{l}-0.007^{* *} \\
(0.003)\end{array}$ & $\begin{array}{l}-0.013^{* *} \\
(0.003)\end{array}$ \\
\hline Child Care time & $\begin{array}{l}-0.004 \\
(0.002)\end{array}$ & $\begin{array}{l}0.005^{*} \\
(0.002)\end{array}$ & $\begin{array}{c}-0.006^{*} \\
(0.002)\end{array}$ & $\begin{array}{l}-0.000 \\
(0.002)\end{array}$ & $\begin{array}{l}0.003 \\
(0.002)\end{array}$ \\
\hline Girl & $\begin{array}{l}0.107^{* *} \\
(0.031)\end{array}$ & $\begin{array}{l}0.510^{* *} \\
(0.028)\end{array}$ & $\begin{array}{l}0.246^{* *} \\
(0.032)\end{array}$ & $\begin{array}{l}0.206^{* *} \\
(0.032)\end{array}$ & $\begin{array}{l}0.018 \\
(0.032)\end{array}$ \\
\hline Age & $\begin{array}{l}0.057^{* *} \\
(0.006)\end{array}$ & $\begin{array}{l}0.085^{* *} \\
(0.006)\end{array}$ & $\begin{array}{l}0.014^{*} \\
(0.006)\end{array}$ & $\begin{array}{l}0.004 \\
(0.006)\end{array}$ & $\begin{array}{l}-0.005 \\
(0.006)\end{array}$ \\
\hline Father Completed High School & $\begin{array}{l}0.304 \\
(0.327)\end{array}$ & $\begin{array}{l}0.027 \\
(0.383)\end{array}$ & $\begin{array}{l}0.951^{* *} \\
(0.257)\end{array}$ & $\begin{array}{l}-0.247 \\
(0.162)\end{array}$ & $\begin{array}{l}-0.293 \\
(0.177)\end{array}$ \\
\hline Father Completed Bachelor & $\begin{array}{l}0.355 \\
(0.327)\end{array}$ & $\begin{array}{l}0.120 \\
(0.383)\end{array}$ & $\begin{array}{l}1.030^{* *} \\
(0.255)\end{array}$ & $\begin{array}{l}-0.249 \\
(0.161)\end{array}$ & $\begin{array}{l}-0.308 \\
(0.175)\end{array}$ \\
\hline Father Completed Postgrad. Degree & $\begin{array}{l}0.312 \\
(0.328)\end{array}$ & $\begin{array}{l}0.087 \\
(0.385)\end{array}$ & $\begin{array}{l}1.056^{* *} \\
(0.258)\end{array}$ & $\begin{array}{l}-0.308 \\
(0.168)\end{array}$ & $\begin{array}{l}-0.323 \\
(0.182)\end{array}$ \\
\hline Mother Completed High School & $\begin{array}{l}0.104 \\
(0.215)\end{array}$ & $\begin{array}{l}0.704^{*} \\
(0.313)\end{array}$ & $\begin{array}{l}0.029 \\
(0.296)\end{array}$ & $\begin{array}{l}-0.064 \\
(0.450)\end{array}$ & $\begin{array}{l}-0.309 \\
(0.405)\end{array}$ \\
\hline Mother Completed Bachelor & $\begin{array}{l}0.176 \\
(0.218)\end{array}$ & $\begin{array}{l}0.733^{*} \\
(0.314)\end{array}$ & $\begin{array}{l}0.249 \\
(0.297)\end{array}$ & $\begin{array}{l}-0.107 \\
(0.450)\end{array}$ & $\begin{array}{l}-0.333 \\
(0.405)\end{array}$ \\
\hline Mother Completed Postgrad. Degree & $\begin{array}{l}0.110 \\
(0.224)\end{array}$ & $\begin{array}{l}0.771^{*} \\
(0.319)\end{array}$ & $\begin{array}{l}0.170 \\
(0.302)\end{array}$ & $\begin{array}{l}-0.165 \\
(0.454)\end{array}$ & $\begin{array}{l}-0.387 \\
(0.409)\end{array}$ \\
\hline Father's Income (10 thous) & $\begin{array}{l}0.005 \\
(0.005)\end{array}$ & $\begin{array}{l}-0.001 \\
(0.005)\end{array}$ & $\begin{array}{l}0.001 \\
(0.005)\end{array}$ & $\begin{array}{l}0.008 \\
(0.006)\end{array}$ & $\begin{array}{l}0.001 \\
(0.005)\end{array}$ \\
\hline Mother's Income (10 thous) & $\begin{array}{l}-0.006 \\
(0.009)\end{array}$ & $\begin{array}{l}0.004 \\
(0.009)\end{array}$ & $\begin{array}{l}0.014 \\
(0.009)\end{array}$ & $\begin{array}{l}0.004 \\
(0.009)\end{array}$ & $\begin{array}{l}0.018 \\
(0.009)\end{array}$ \\
\hline$\%$ of Australian born by postcode & $\begin{array}{l}0.000 \\
(0.002)\end{array}$ & $\begin{array}{l}-0.001 \\
(0.002)\end{array}$ & $\begin{array}{l}0.002 \\
(0.002)\end{array}$ & $\begin{array}{l}-0.001 \\
(0.002)\end{array}$ & $\begin{array}{l}0.003 \\
(0.002)\end{array}$ \\
\hline$\%$ completed High School by postcode & $\begin{array}{l}-0.001 \\
(0.002)\end{array}$ & $\begin{array}{l}0.001 \\
(0.002)\end{array}$ & $\begin{array}{l}0.001 \\
(0.002)\end{array}$ & $\begin{array}{l}-0.000 \\
(0.002)\end{array}$ & $\begin{array}{l}0.002 \\
(0.002)\end{array}$ \\
\hline
\end{tabular}

For father and mother education the reference category is "High School not completed";

The estimated coefficients for the Period 2 - OLSb specification, including both Wave 1 and Wave 2 variables, are available upon request. 


\section{Acknowledgements}

I wish to thank an anonymous referee, Michael Keane, Jerome Adda, Steve Pischke, Ian Walker, Bruce Bradbury, Katrien Stevens and workshop participants at the Econometric Society European Meetings 2008, University of Melbourne, University of South Australia, Econometric Society Australasian Meeting 2008 and Australian National University for helpful comments.

\section{Vitae}

In August 2007 I was appointed as a Lecturer in Economics in the School of Finance and Economics, University of Technology Sydney (UTS). Prior to this appointment I was enrolled as a $\mathrm{PhD}$ student in Economics at University College, London (UCL). My main research interest is in the determinants of child development, both cognitive and non-cognitive. I also have a strong interested in educational choices and intergenerational mobility. 


\section{References}

Angrist, J., AND V. LAVY (2002): "New Evidence on Classroom Computers and Pupil Learning," Economic Journal, 112(482), 735-765.

Baker, M., AND K. Milligan (2008): "Evidence From Maternity Leave Expansions of the Impact of Maternal Care on Early Child Development," Journal of Human Resources, forthcoming.

Banerjee, A., S. Cole, E. Duflo, And L. Linden (2007): "Remedying Education: Evidence from Two Randomized Experiments in India," Quarterly Journal of Economics, 122(3), $1235-1264$

Barrow, L., L. Markham, And C. E. Rouse (2009): "Technology's edge: the educational benefits of computer-aided instruction," American Economic Journal: Economic Policy, forthcoming.

Beltran, D. O., K. K. Das, And R. W. Fairlie (2008): "Are Computers Good for Children? The Effects of Home Computers on Educational Outcomes," CEPR Discussion Papers 576, Centre for Economic Policy Research, Research School of Social Sciences, Australian National University, forthcoming in Economic Inquiry.

Berlinski, S., S. Galiani, And M. Manacorda (2008): "Giving children a better start: Preschool attendance and school-age profiles," Journal of Public Economics, 92(5-6), 14161440 .

Bernal, R., And M. P. Keane (2009): "Quasi-Structural Estimation of a Model of Child Care Choices and Child Cognitive Ability Production," Journal of Econometrics, forthcoming.

Cameron, S. V., And J. J. Heckman (1998): "Life Cycle Schooling and Dynamic Selection Bias: Models and Evidence for Five Cohorts of American Males," Journal of Political Economy, 106(2), 262-333.

(2001): "The Dynamics of Educational Attainment for Black, Hispanic and White Males," Journal of Political Economy, 109(3), 455-499.

Cunha, F., And J. J. Heckman (2007): "The Technology of Skill Formation," American Economic Review, 97(2), 31-47.

Cunha, F., J. J. Heckman, And L. Lochner (2006): Interpreting the Evidence on Life Cycle Skill Formationvol. 1 of Handbook of the Economics of Education, chap. 12, pp. 697-812. Elsevier.

DAhl, G. B., AND L. Lochner (2005): "The Impact of Family Income on Child Achievement," Working Paper 11279, National Bureau of Economic Research.

Gentzkow, M., And J. M. Shapiro (2008): "Preschool Television Viewing and Adolescent Test Scores Historical Evidence from the Coleman Study," Quarterly Journal of Economics, 123(1), 279-323.

Gurian, M. (2002): Boys and Girls Learn Differently! John Wiley and Son.

Heckman, J. J., J. Stixrud, And S. Urzua (2006): "The Effects of Cognitive and Noncognitive Abilities on Labor Market Outcomes and Social Behavior," Journal of Labor Economics, 24(3), 411-482.

Keane, M. P., AND K. I. Wolpin (1997): "The Career Decisions of Young Men," Journal of Political Economy, 105(3), 473-522. 
(2001): "The Effect of Parental Transfers and Borrowing Constraints on Educational Attainment," International Economic Review, 42(4), 1051-1103.

Rouse, C. E., And A. B. Krueger (2004): "Putting Computerized Instruction to the Test: a Randomized Evaluation of a Scientifically-Based Reading Program," Economics of Education Review, 23(4), 323-338.

Schmidt, M. E., And D. R. Anderson (2007): Children And Television: Fifty Years of Researchchap. 3, pp. 65-84. Routledge.

Schmitt, J., AND J. WADSworTh (2006): "Is there an impact of household computer ownership on childrens educational attainment in Britain?," Economics of Education Review, $25(6), 659-673$.

Subrahmanyam, K., P. Greenfield, R. Kraut, and E. F. Gross (2001): "The impact of computer use on children's and adolescents' development," Journal of Applied Developmental Psychology, 22(1), 7-30.

Subrahmanyam, K., R. E. Kraut, P. M. Greenfield, and E. F. Gross (2000): "The Impact of Home Computer Use on Children's Activities and Development," .

Todd, P. E., AND K. I. Wolpin (2003): "On the Specification and Estimation of the Production Function for Cognitive Achievement," Economic Journal, 113(485), 3-33.

(2007): "The Production of Cognitive Achievement in Children: Home, School, and Racial Test Score Gaps," Journal of Human Capital, 1(1), 91-136. 